مجلة الدراسـات التربوية والنفسية- جامعة السـلطان قابوس مجلم DOI: http://dx.doi.org/10.24200/jeps.vol13iss3pp558-575

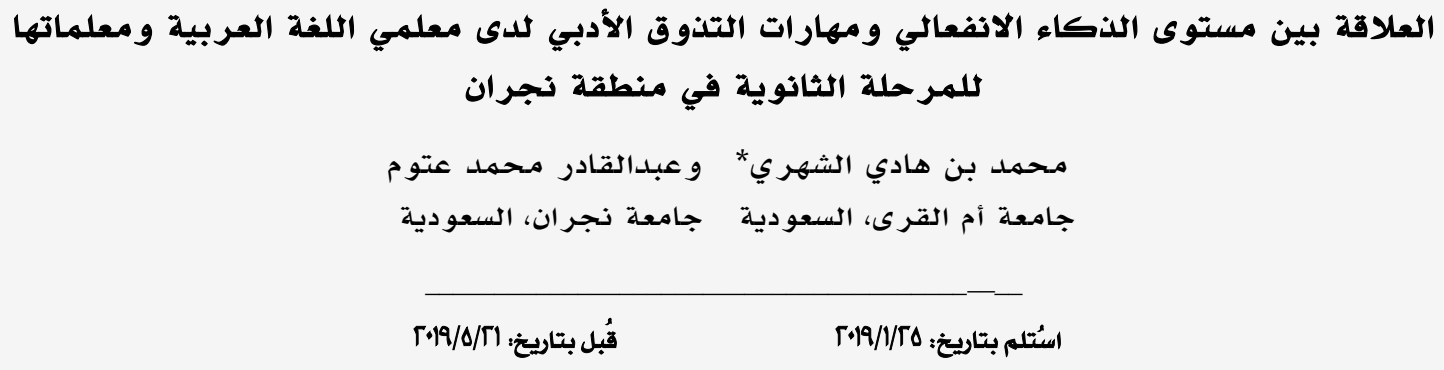

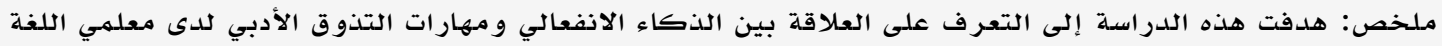

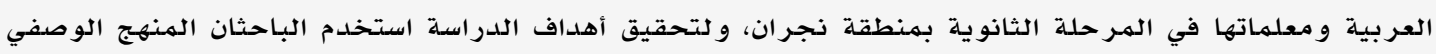

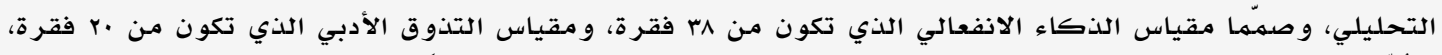

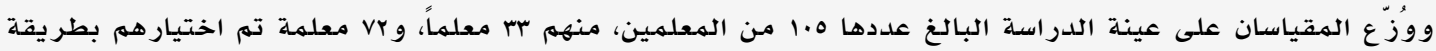

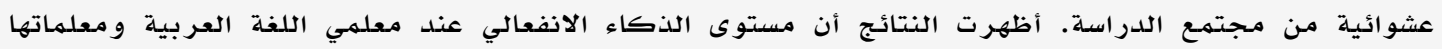

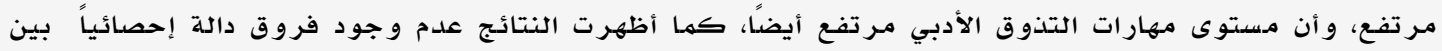

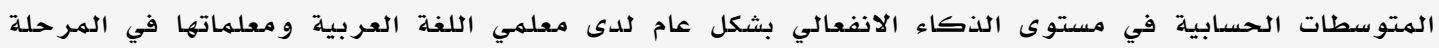

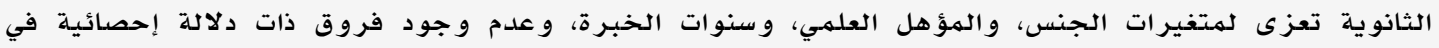

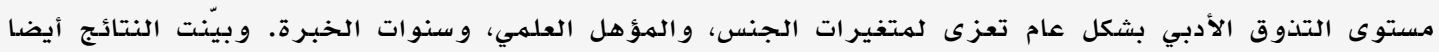

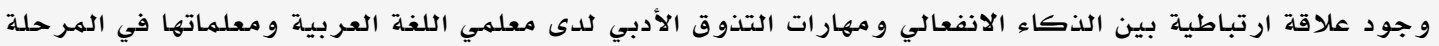

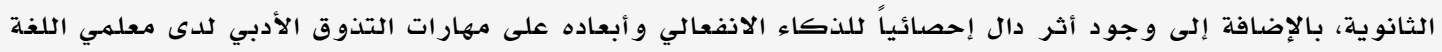

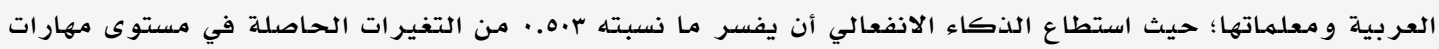

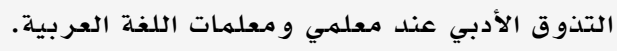
كلمات مفتاحية : الذكاء الانفعالي؛ التذوق الأدبي؛ معلمي اللغة العربية ومعلماتها.

\title{
The Relationship between Emotional Intelligence and the Level of Literary Appreciation Skills among Arabic Language Teachers for the Secondary Stage in Najran Region
}

Mohammed H. Alshehri* \& Abdalgader M. Atoom

Umm Al-Qura University, Saudi Arabia Najran University, Saudi Arabia

Abstract: The study aimed at identifying the relationship between emotional intelligence and the level of literary appreciation skills among Arabic language teachers for the secondary stage in Najran region. To achieve this aim, the researchers used the descriptive analytical method. The researchers used two questionnaires; the first one was to measure the level of emotional intelligence, which consisted of 38 items, and the second one was to measure the level of literary appreciation scale, which consisted of 20 items. The research sample consisted of 105 teachers chosen randomly, 28 males and 77 females. The results of the study indicated that the level of emotional intelligence and the level of literary appreciation skills among the teachers was high. There were no statistically significant differences at the level of emotional intelligence attributed to the variables of gender, qualification, and experience, and there were no statistically significant differences at the level of literary appreciation skills attributed to the variables of gender, qualification, and experience. In addition, the results indicated that there was a significant correlation between the level of emotional intelligence and the level of literary appreciation skills. There was a statistically significant effect of emotional intelligence and its dimensions on the level of literary appreciation skills among Arabic language teachers. Emotional intelligence was able to explain 0.503 of the variances in the level of literary appreciation skills among teachers of Arabic language.

Keywords: : Emotional intelligence, literary appreciation skills, Arabic language teachers.

$\star$ ama jordan@yahoo.com 
وتشهمل أنواع الذكاءات المتععددة مـا يلي: اللغوي، و الهكاني، و الموسيقي، و الاجتهاعي،

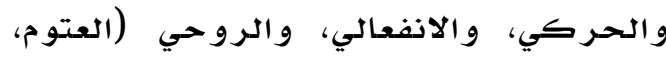

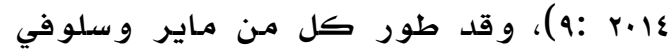
(mayer and salovey, 2000)

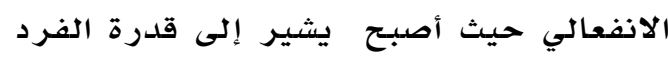
على مر اقبة المشاعر والانفعالات، والتمييز التهيز

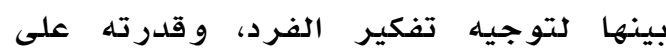

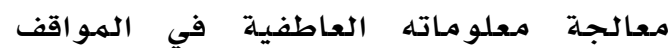

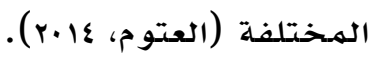

و عرف مبيض (r.r.r: rا) الذكاء الانفعالي

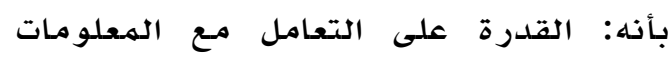

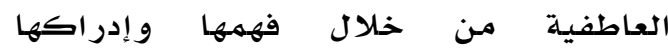

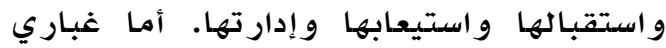

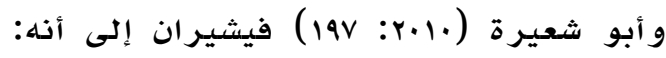

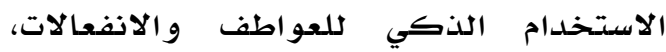
فالفرد يستطيع أن يجعل عواطفه تعمل من أن أن

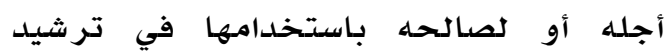

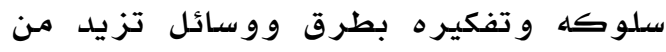

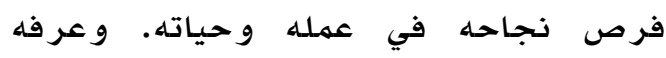
جورج (George, 2000) بالقدرة على إدرالك

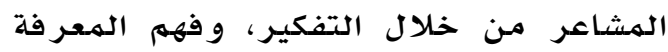
الانفعالية، وتنظيم المشاعر بحيث يستطيع الفرد أن يؤثر في مشاعر الآخر ين.

و أكد بار - اون (Bar- On, 2000) أن

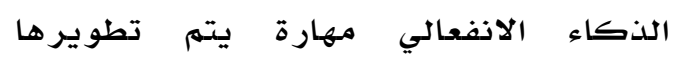
واكتسابها من خلال براء امـج تدريبية معينة

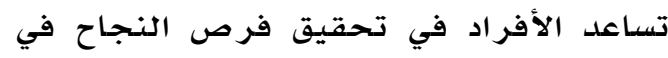
حياتهم، وتقلل نسبة حلدوث المشاكل

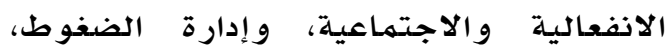

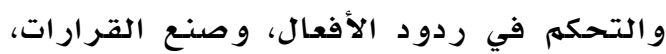

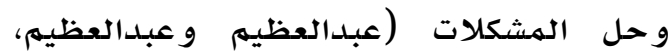
. $(\varepsilon \wedge:$ r...

ويرى كل من فريدمان (freedman, 2007)

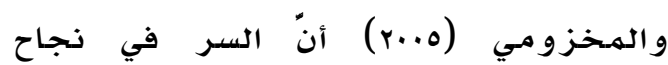

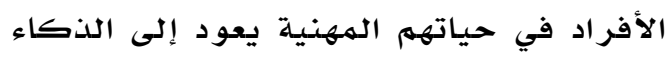

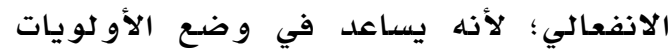

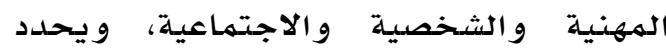

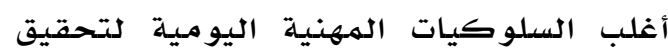

تعدّ الانفعالات من أهم مكونات شخصية

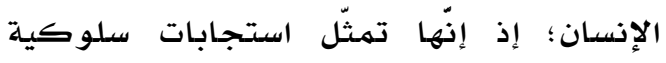

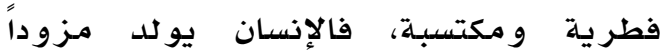

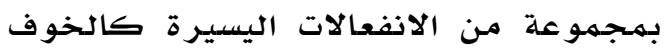
و الفرح والغضب، و ولكن تلك ألخد الانفعالات تأخذ أبعاداً أخرى، والفران، وتصبح أكثر تركيباً

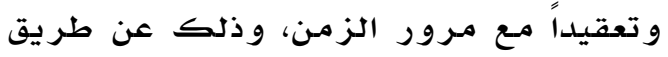

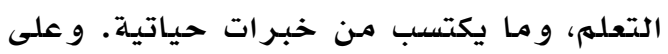

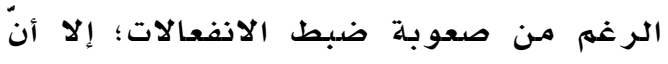
ذلك لا يقلل من كونها تضفي معنى لحياة

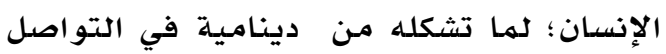
بين البشر ، كما أنها تؤثر في سلوكهم عند تعاملهم مـع ذواتهم، ومـع الآخرين، والأثياء

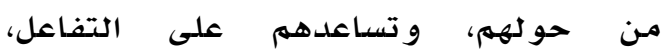
و التكيف في مختلف ظرو فهم الحياتية. و يختلف الأفر اد في سرعة إدراكهم للحالات

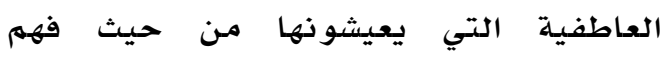

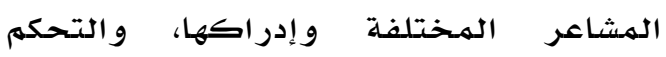

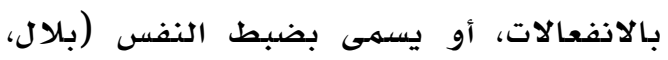
. $(r \cdot 1 \varepsilon$

والانفعالات السلبية والإيجابية تعدّ ضرورية

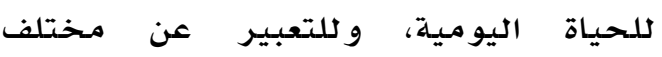

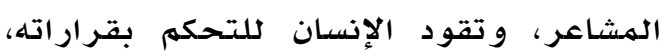

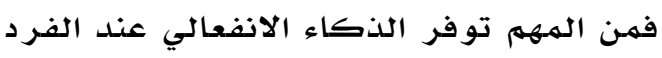

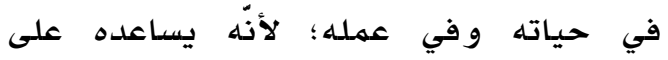
الرقي و التقدم نحو الأفضل (العتوم، عالـr). وقد سيطرت فكرة أن" الذكاء واحد لفترة طويلة من الزمن، حتى ظهرت مـوجة جديدة الديدة تشير إلى وجود أنواع مختلفة من من الذكاء؛

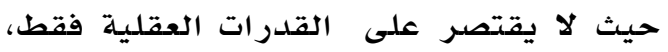
بل يتطلب لنجاح الفرد في أي موقف وجوداد ذكاءات متعددة لديه، و فسر الباحثون نجاح الأفر اد في حياتهم العملية على الرغم من فن فئن

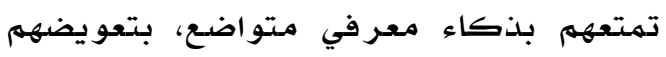
ذلك بها يمتلكونه من هفاءات اتفعالية

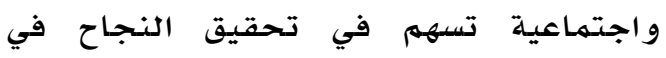
حياتهم العملية في جميع المهالات. (بلاهل، (ir: r. Is 
الضرورية لإدراك الهفاهيم، والقدرة على

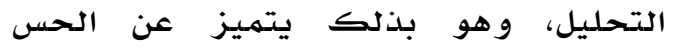
و الحواس.

وتعد الظواهر التذوقية و الجمالية من أعقد

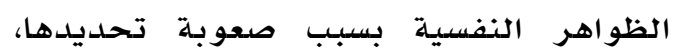
و معرفة طبيعتها بصورة فعلية، و في مقدمة

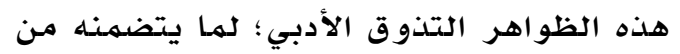

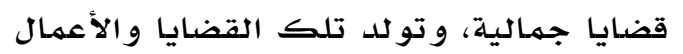
الفنيـة تذوقاً على شكل استجابة، وتولة انفعالية،

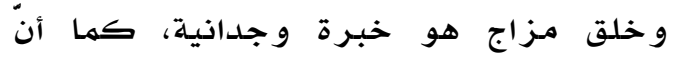
التذوق في جوهره خبرة تأملية همالية تتكون من الاستمتاع بالجوانب السيكو لوجية

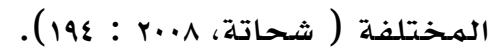

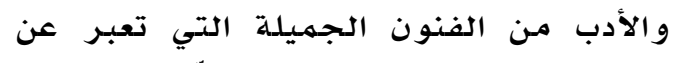

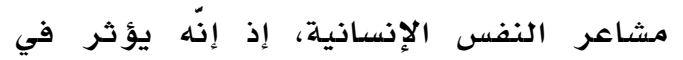

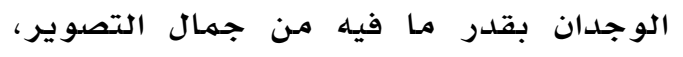

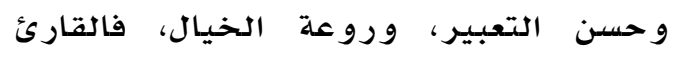

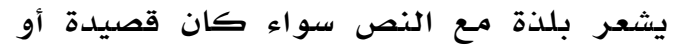
مقالاً أو قصة لبلذة جديدة النهي كتلك اللذة التي

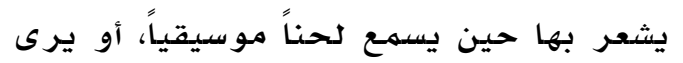

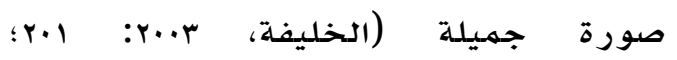

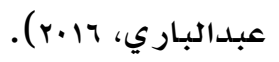

و يعرف الركابي (ه..r: rیا) التذوق الأدبي

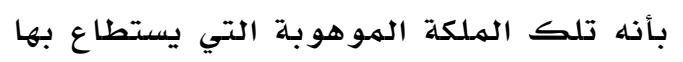

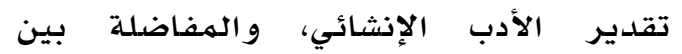

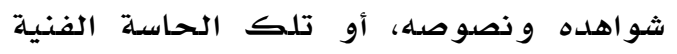

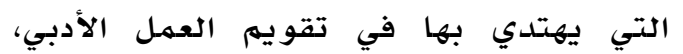

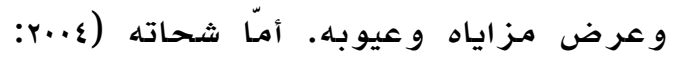

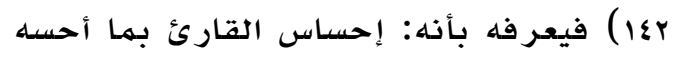
الشاعر أو الكاتب.

وتركز تعريفات التذوق الأدبي على جوانب

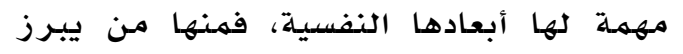

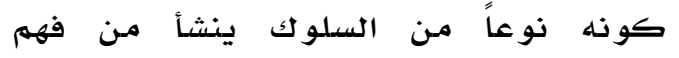

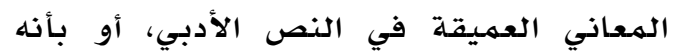

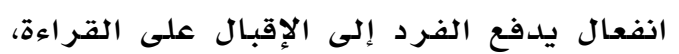

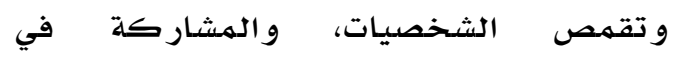

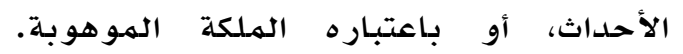

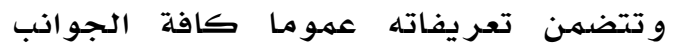
المعرفية، و الوجدانية، و الههارية.
النجاح في الههنة، وهذا ما أكدته فاينسنت مـن أن" الذكاء العام وحده (Vincent, 2003) لا يكفي لضمان نجاح الفرد في الهواقف الحياتية، و إنما يحتاج إلى الذكاء الذهاء الانفعالي

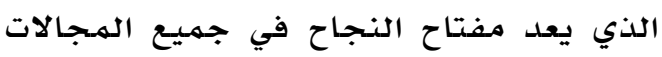
الأكاديمية و الشخصية و المهنية.

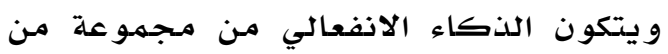

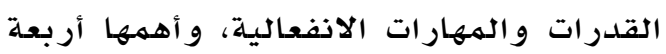
أبعاد ستركز عليها هذه الدراسـة، وهي: المعرفة الانفعالية: وهي القدرة على

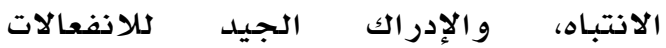

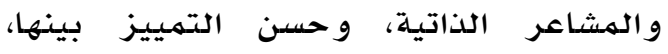

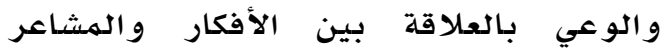
الذاتية والأحداث الخارجية. ماير و وسالوفي .(Mayer \& Salovey, 2000)

إدارة الانفعالات: القدرة على التحكم في الانفعالات السلبية، وادهسب الوقت للتحكم فيها وتحويلها إلى انفعالات إيجابية. ماير ولدرابر و سالوفي (Mayer \& Salovey, 2000).

التواصل مـ الآخرين: التأثير الإيجابي،

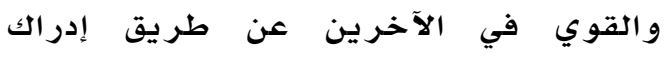

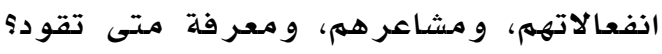

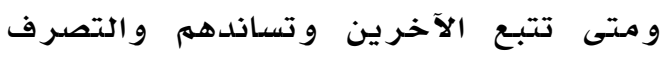

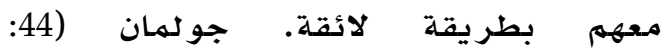
.(Goleman, 1995

الدافعية: ووهي اعتماد الفرد على قوة داخلية تدفعه نحو تحقيق الأهداف، كالمتعة في الميه العمل، وحب التعلهم، وتشمل حافز الإنجاز، التهول

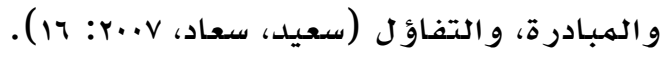
و لقد حظي الذكاء الانفعالي الذي يسمى

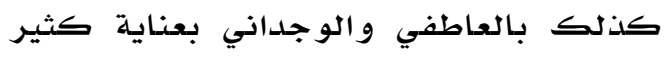
من الباحثين في الهـالات التربوية ؛ لأهميته

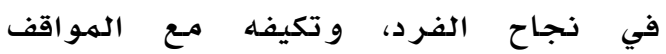

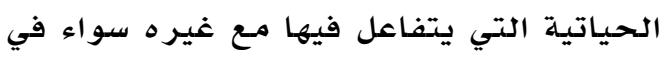
المدرسة، أو الهجتهمع. و في هذ الصدي الدد يشار

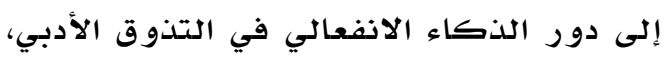
و ذلك من خلال مـا أثار إليه علوان (11)

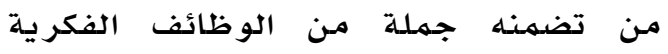


و تتطور قدرته على تحليل النصوص

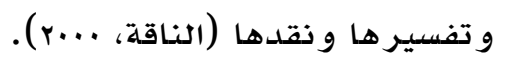

و للمعلهم دور في تنهية التدوق الأدبي عند طلبته، من خلال إيمانه بأن كل طالب لديه دوريه القدرة على ذلك، و تدريبهم على ذلك مبه بعقد

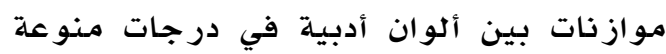

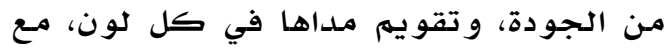
ضرورة توافر الحاسـة الأدبية عند الهودة الهعلهم

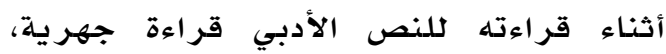
فالمتعلهم يتأثر بأداء المعلهم، كماء أن" الأداء الجيد عنصر مهمم في تذوق النص الأدبي

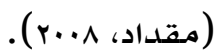

ومن خلال ما سبق؛ تتضح أهمية التذوق

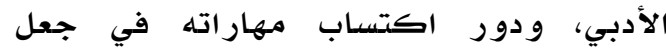

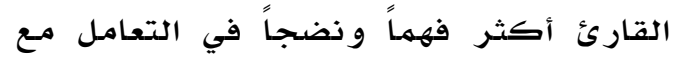
النصوص الأدبية، وهو ما جعل التذوق الأدبي

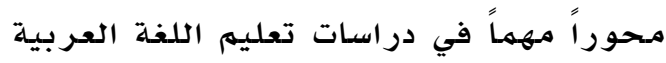

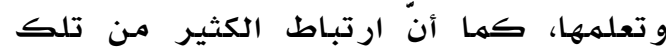

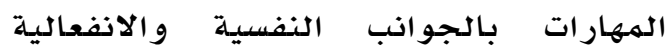

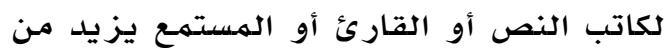

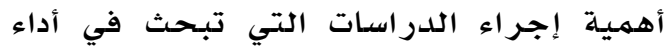

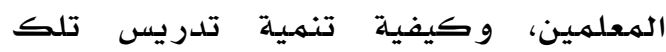
الههارات لديهم، وربطه بجانب مهم وهو الذكاء الانفعالي، مهما ينعكس إيجابًا على ورلى الطلاب.

و لقـــد أكــدت العديـــد مــن الدرراســات دور

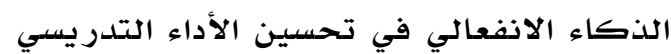

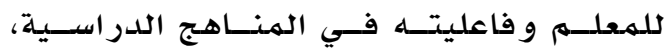
و تفعيـل عمليــة الـتعلهم، و تحقيـق الإنجــاز

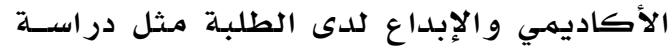

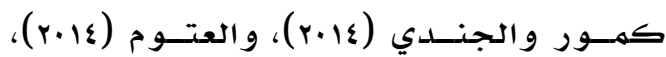

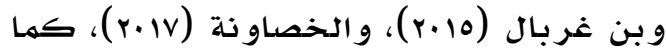

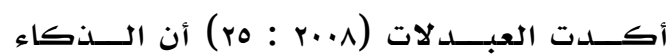
الانفعالي يؤدي دوراً مهما في تعليم الطلبـة أهـا

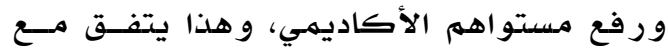

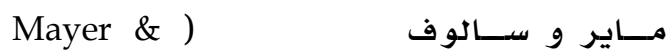
(Salovey, 2000

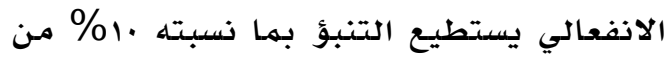

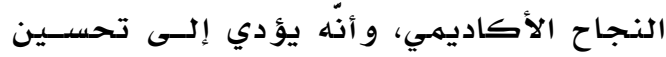

و تتضمن عملية التذوق الأدبي في بعدها النفسي و الجمـالي العنصر يين التاليين: الجانب الوجداني: ويقصد بـ تمثل القارئ أحاسيس الكاتب، و قدرته على أن يستشف ولى الحالة النفسية التي يعبر عنها في فهمهـ.

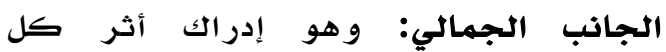
جزئية في النص، ودورها في مـجال الفكرة،

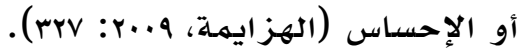

ويؤدي الأدب وظائف نفسية وجمالية أهمها: يصور ما يدور في النفس الإنسانية

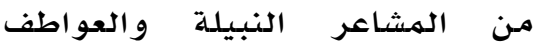

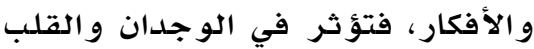

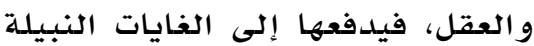

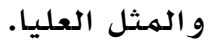

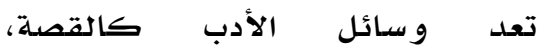
و الروواية، و المسرحية و سـائل مهممة

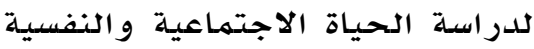

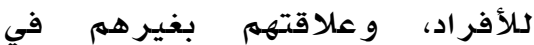
مجتمعهمه.

تصوير الطبيعة بما حباها الله تعالى من سحر، وجمال (الخليفة، r..r: . $(r \cdot r$

وون أبرز ما يهدف إليه تدريس الأدب في هذا الهـجال مـا يلي:

مسـاعدة الطلبة على فهم النصوص الأدبية، و إدراك مواطن الجمال فيها و تذو قها و تحليلها.

مساعدة الطلبة على فهم أنفسهم، وحل مشكلاتهم، وتوجيه حياتهم

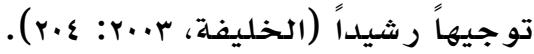
و يزداد الاهتمام بالتذوق الأدبي في الهـرحلة

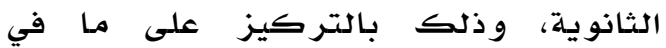
النصوص من عواطف و مكونات جمالية

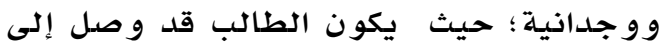
مستوى معين من النضج في كافة الجوانب

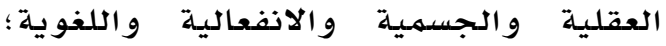

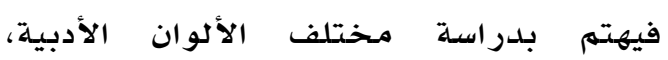


إسهام الذكاء الانفعالي في التوافق المهني

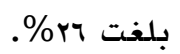

أما دراسة كمور و والجندي (عا.ب) فقد أظهرت في نتائجها وجود علاقة ارتباطية

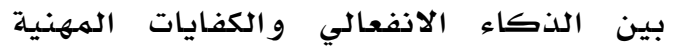
و الشخصية و الاجتماعية.

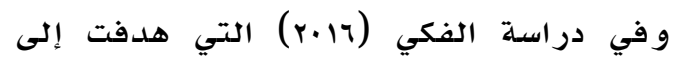
التعرف على العلاقة السببية بين الدئي الذكاء

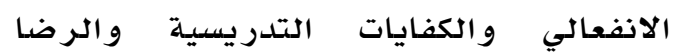
المهني لدى معلمي التربية الخاصدة، أظهرت النتائج وجود درجة مرتفعة لمستوى الذكاء لأناء

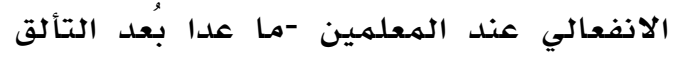

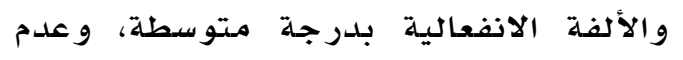

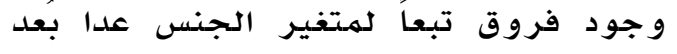
التعاطف و التفهم الانفعالي لصالح المعلمين، وعدم وجود فروق تبعاً لمتغير التأهيل

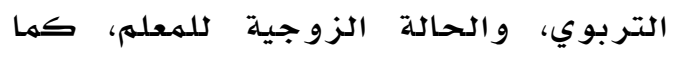
توجد علاقة ارتباطية بين الذكاء الانفيات النفالي و الكفايات التدريسية.

من ناحية أخرى، أجرى الخصاونة (Y.lV)

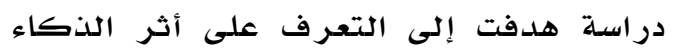

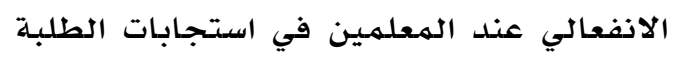

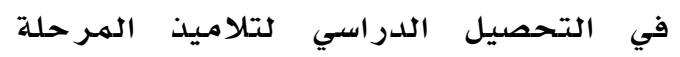

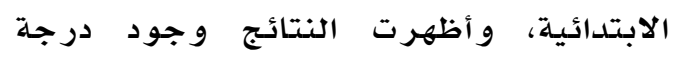

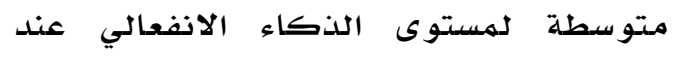

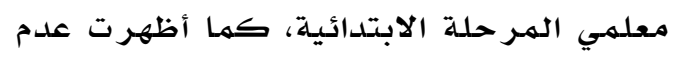

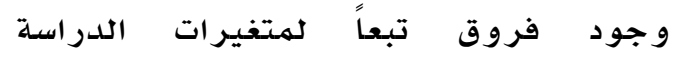

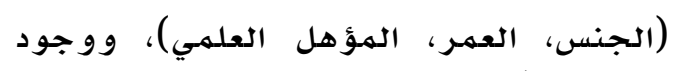
فروق تبعاً لمتغير الخبرة الهوهل الوظيفية.

و في الدراسات ذات العلاقة بالتذوق الأدبي؛

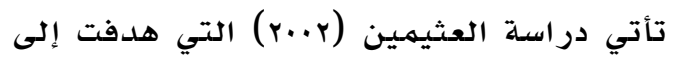

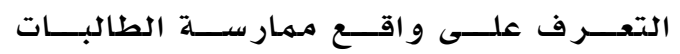

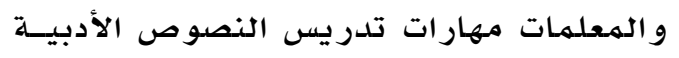

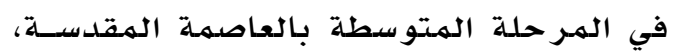

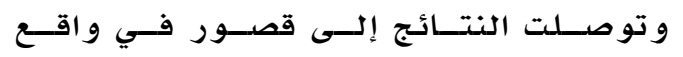

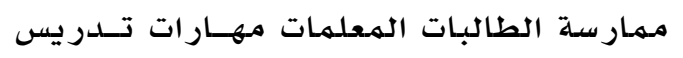

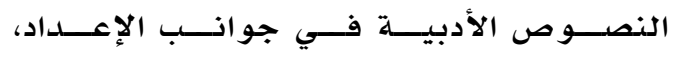

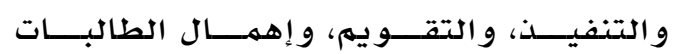

التحصيل الأكاديهي، ورفع مسـتوى الـوعي بالذات، و إدارة الانفعالات فـي محسيط بيئسة التهية التعلهم.

ويمكن تناول الدراسات ذات الصلة بالـذكاء

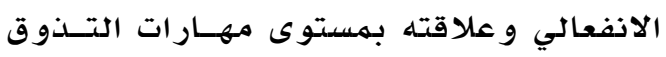

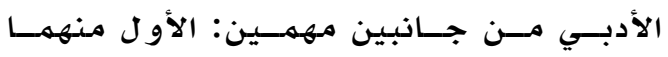

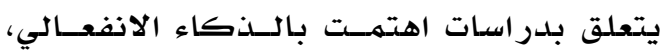

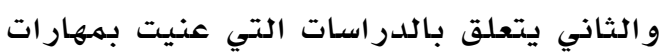
التذوق الأدبي.

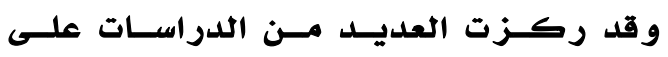

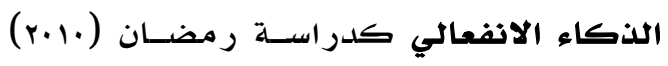

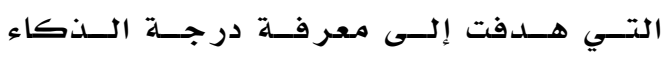

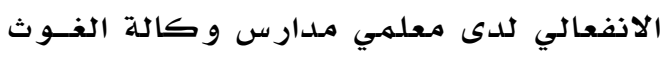

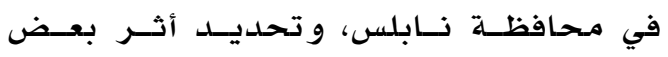

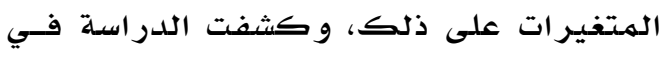

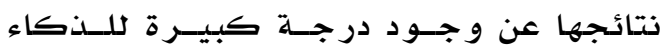

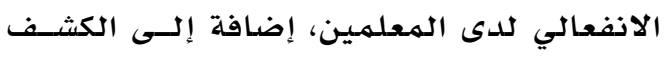

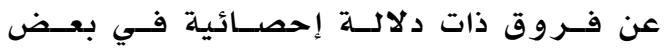

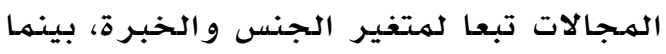

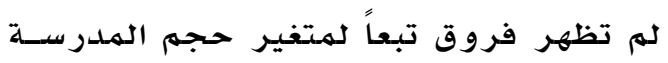

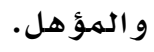

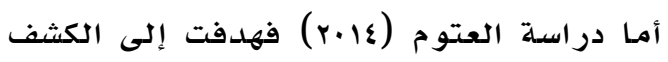

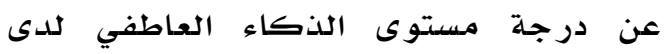
معلمات الصفوف الثلاثة الأو لى في محافظة الذاء العاطفي

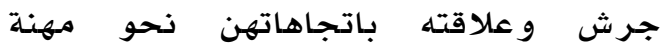

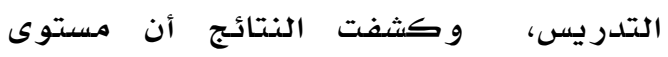

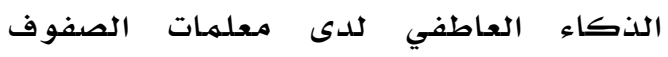
الثلاثة الأولى في المحافظة كان العان متوسطاً،

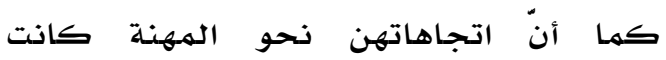
متوسطة، وظهر وجود علاقة ارتباطية

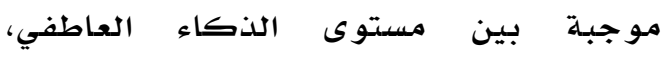
واتجاهات المعلمات نحو مهنة التدريس. و في دراسة الفيلكاوي (10.r) التي هدفت التي

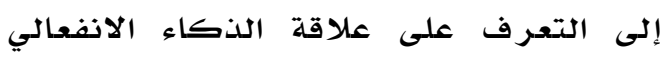

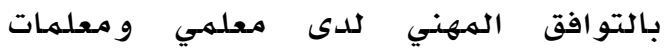

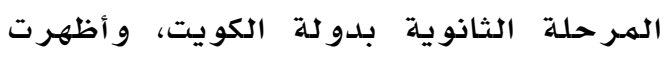

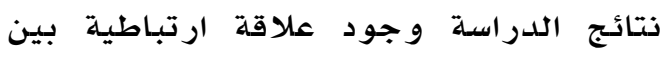

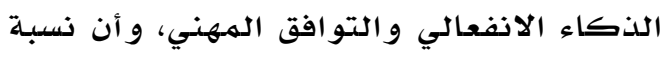




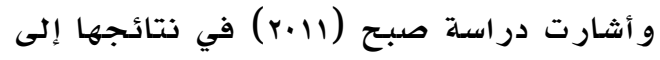

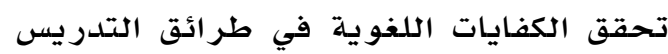

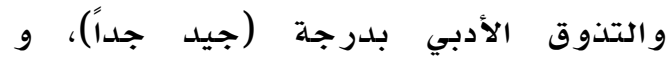

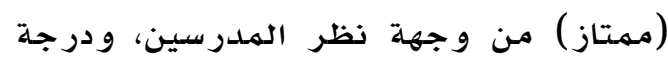

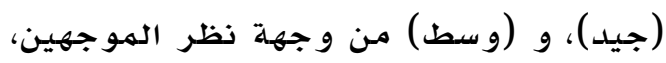

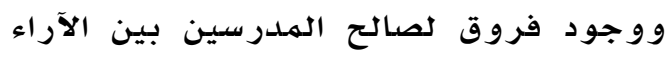

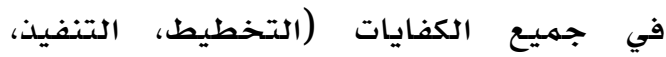

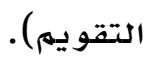

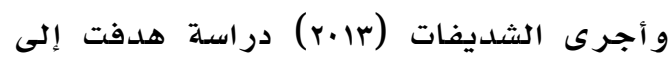

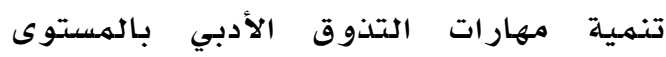
الإبداعي من خلال بناء برنامجج تعليمي قائم التادي

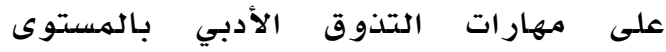
الإبداعي من خلال تلدريس نصوص أدئ أدبية

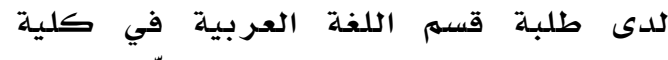

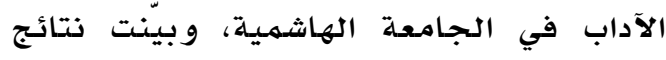
الدراسة وجود فروق ذات دلالة إحصائية

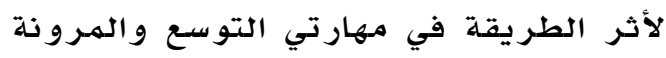

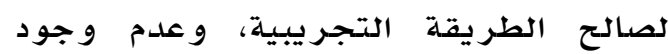
فروق ذات دلالة إحصائية في مهارتي التئية

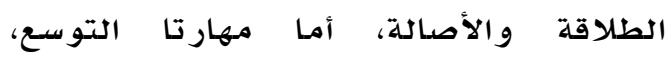

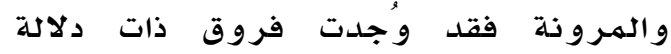

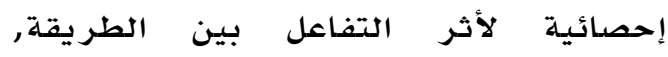
والجنس, و عدم وجود فروق ذات دلالة لاتلة

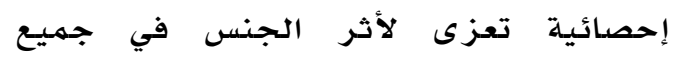

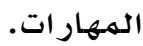

\section{مشكلة الدراسة - م اسة}

كشفت بعض الدراسات مثل دراسة إبراهيم

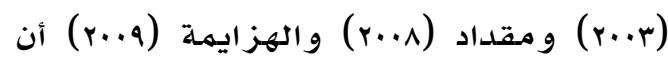
بعض أسباب عدم إتقان الطلبة لمهارات

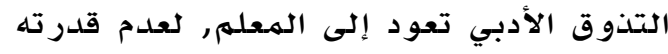

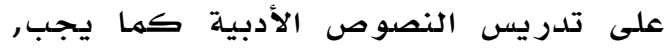
وعدم وقوفه على مواطن الجمال, و الخيال،

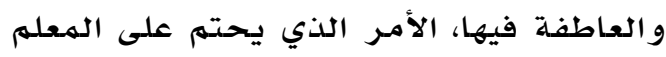

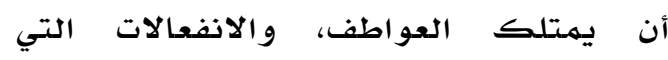

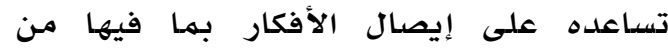

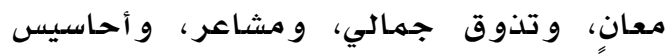

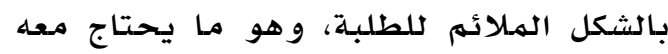

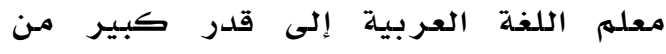
الذكاء الانفعالي لوصف الحركة النفسية الفية
المعلمات المهارات التي تسـاعد علسى تنميسة التذوق الأدبي عند التلميذات.

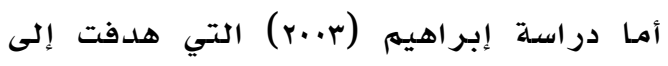

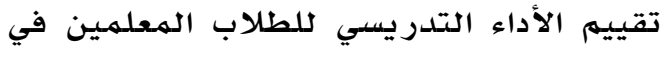

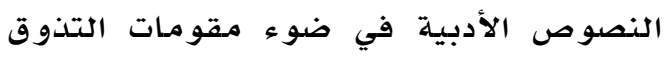
الأدبي، فتوصلت إلى أن مستوى الأد مقدمات الأداء

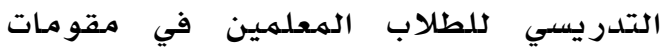

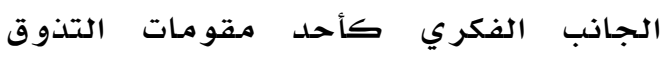

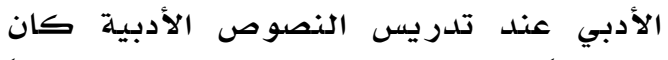

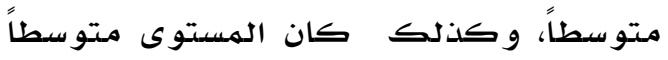
في مقومات الجانب الوجداني.

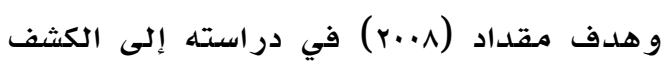

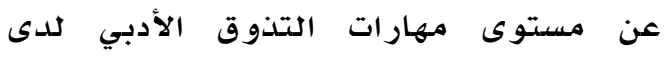
معلمي اللغة العربية بالمرحلة الأساسية التانية

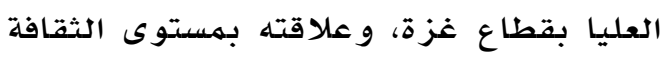

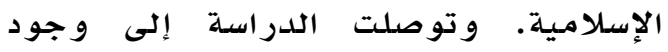

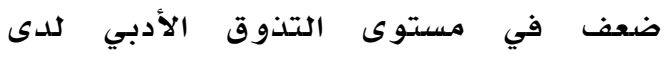

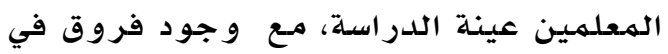

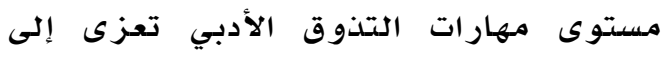

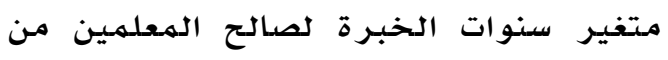

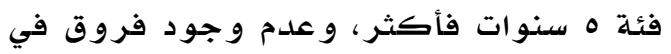

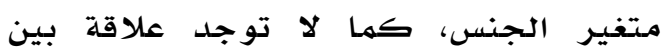

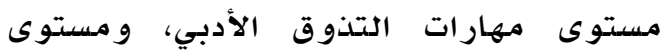

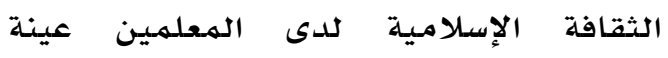

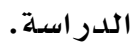

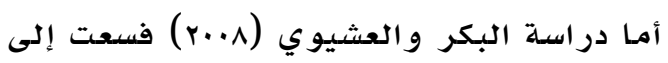

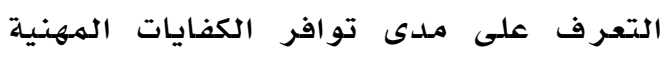

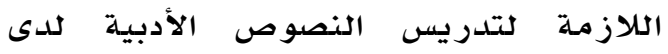

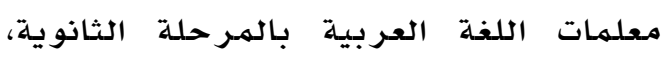

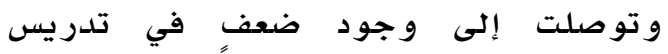
النصوص الأدبية لدى المعلمات عينة الدراسلة

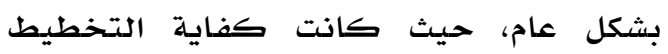

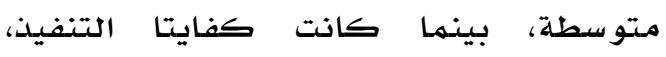
و التقويم ضعيفة.

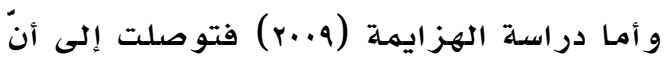

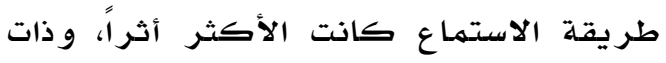

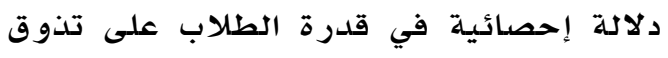

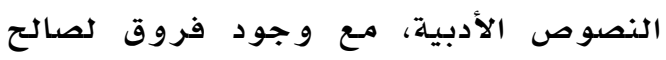
الإناث في مهارات التذوق الأدبي. 


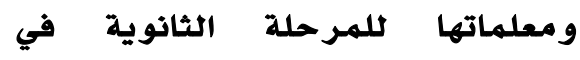

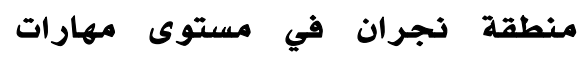

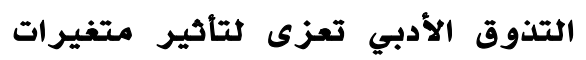

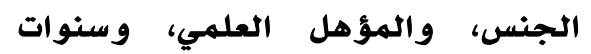

الخبرة الجهئ

0. هل يمكن التنبؤ بمستوى مهارات

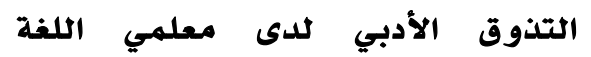

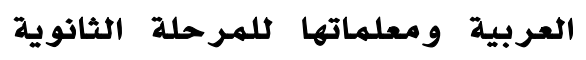

من خلال الذكاء الانفعالي، ومكوناته

الفر عية؟ الون

أهداف الدراسة

تهدف هذه الدر اسلة إلى:

1. التعرف على مستوى الذكاء الانفعالي

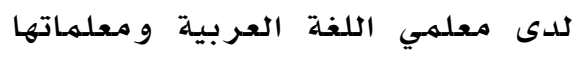

للمر حلة الثانوية في منطقة نجر ان.

r. التعرف على مستوى مهارات التذوق

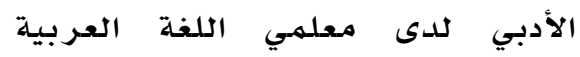

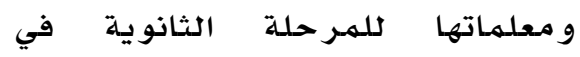

منطقة نجر ان.

r. التعرف على الفروق في الذكاء

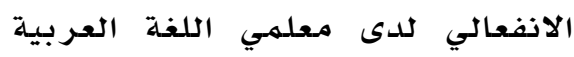

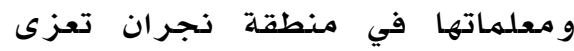

لتأثير متغير ات الدراسة.

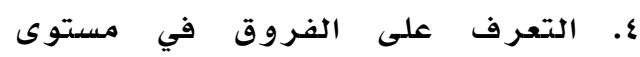

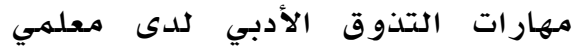

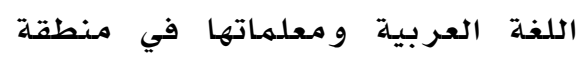

نجران تعزى لتأثير متغيرات الدراسلة.

ه. التعرف على العلاقة الارتباطية بين

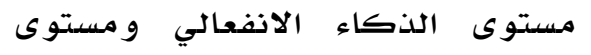

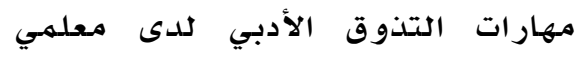

اللغة العربية و معلماتها في منطقة التهات

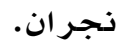

T. تحديد درجة إسهام الذكاء الانفعالي

بمستوى مهارات التذوق الأدبي لدى الدى الديل

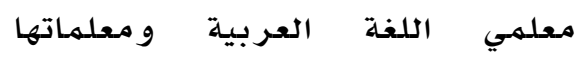

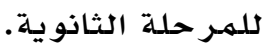

الخاصة بالشاعر، أو الأديب كما تظهر في

النص الأدبي، وذلك باستقراء شعور الطلاب،

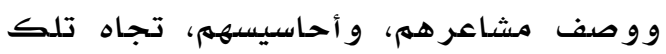

النصوص، وتكون الأسئلة، والمناقشة أساس ولهاس

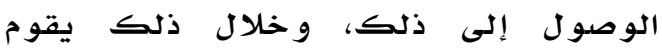

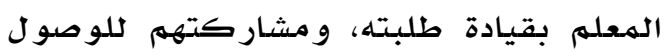

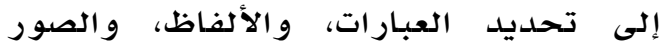

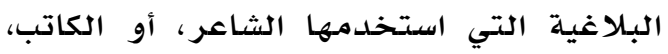

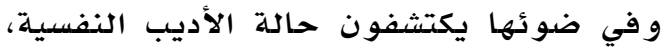

و الظروف التي أحاطت به، و أثرت فيه.

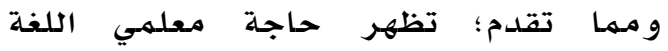

العربية إلى الذكاء الانفعالي لتنمية مهار اتلة معلهي

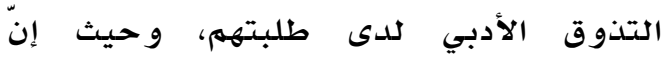

الباحثين لهم يطلعا على دراسات بحثت في الكاتئ

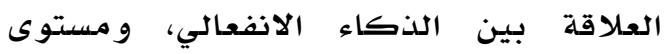

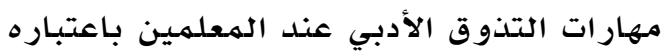

من أهم الصفات التي يجب أن تتوافر التدي عند الهعلدين باعتباره

معلهي من اللغة العربية لتمكنهم من الهن أداء

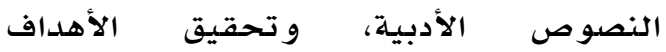

التدريسية اللازمة ؛ فقد جاءت الادبة مشكلة هلده

الدراسة، والتي حاولت الإجابة عن الأسئلة

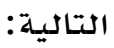

1. ما مستوى الذكاء الانفعالي للى الدئ

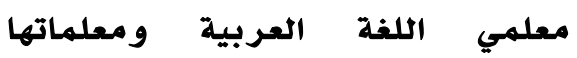

للمرحلة الثانوية في منطقة نجران

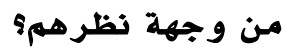

r. هل توجد فروق دالة إحصائيًا عند

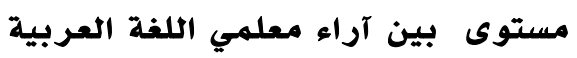

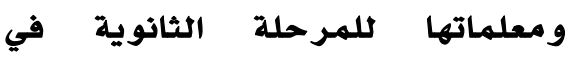

منطقة نجران في مستوى الذكاء

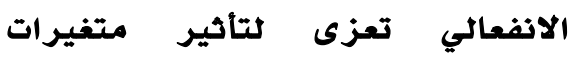

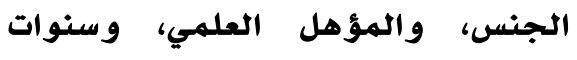

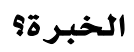

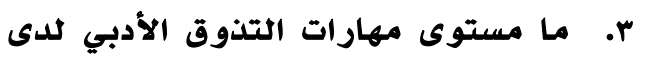

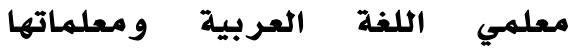

للمرحلة الثانوية في منطقة نجرئ العران

التي يراعونها في تدريسهم للطلبة من فئن

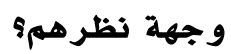

ع. هل توجد فروق دالة إحصائيًا عند

مستوى بين آراء معلمي اللغة العربية دوف إحلية 
ويقاس ذلك من خلال الإجابة عن فقرات أهمية الدراسة

المقياس الذي تم تطوير هـ لهذه الغاية. التذوق الأدبي (إجرائيا): النشاط الإيجابي

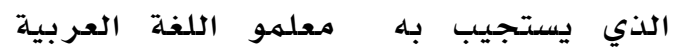

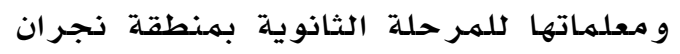

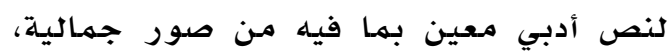
و فنية، و عواطف، و أحاسيس، و مشاعر ، و التي مئي

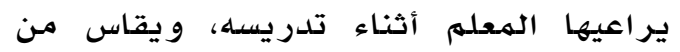
خلال الإجابة عن فقرات المقياس الذي تم تطويره لهذه الغاية.

\section{إجر اءات الدراسة}

\section{منهج الدراسة}

استخدمت الدراسـة الهنهج الوصفي التحليلي،

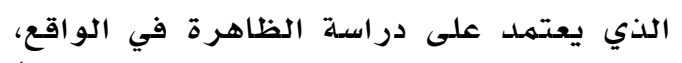

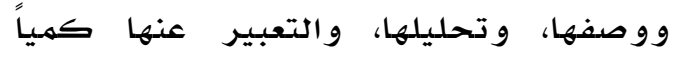
و كيفاً، وذلك وونا، ونن طريق تطبيق الأدوات

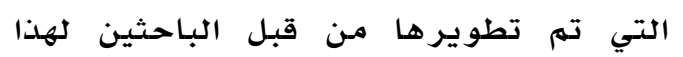

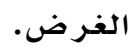

\section{مجتمع الدراسة وعينتها}

تكوّن مجتتمع الدراسـة من جميع معلمي اللغة

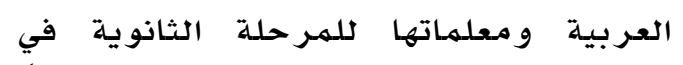
منطقة نجران، والبالغ عددهمر (191) معلمهاً،

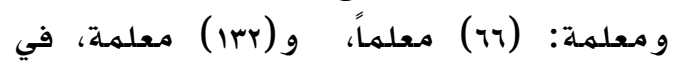

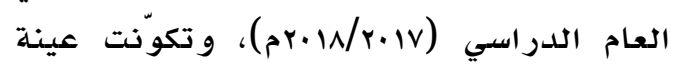

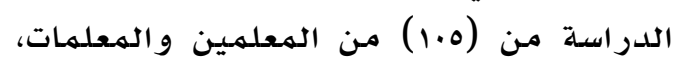

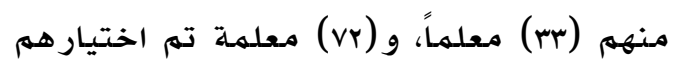

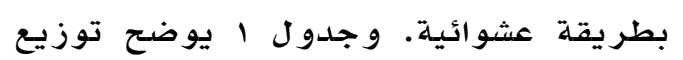

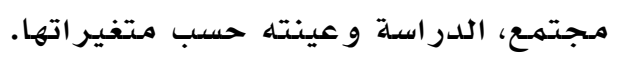
جدول الاروة

توزيع أفراد عينة الدراسة بحسب متغيرات الدراسة

\begin{tabular}{|c|c|c|c|}
\hline النسبة المئوية & التكرار & الفئات ل & المتغير \\
\hline M. & אr & ذكر & \\
\hline 71.7 & $V Y$ & أنثى & الجنس \\
\hline ir.r & $1 \leq$ & اقل من r سنوات & \\
\hline rr.A & ro & من ץ إلى 7 سنوات & ستر \\
\hline $7 r .9$ & 77 & أكثر من 7 سنوات & الحبرة \\
\hline ҮА. & VY & بكالوريوس & \\
\hline r... & rr & بكالوريوس+ دبلوم & tall \\
\hline $1 . .0$ & 11 & ماجستير & \\
\hline
\end{tabular}

ا. تناولت الذكاء الانفعالي لمعلمي اللغة

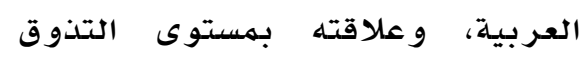

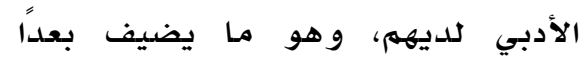

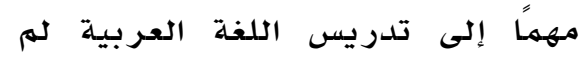

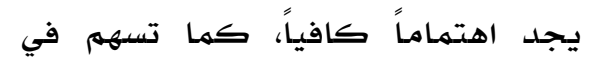

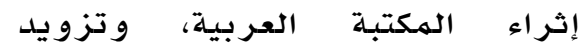
الباحثين بأطر نظرية في هذا المجال. r. تفيد القائمين على العملية التربوية

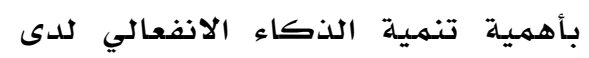

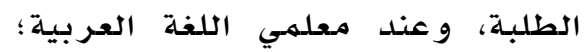
لأنه يرتبط بشكل مباشر بههارات

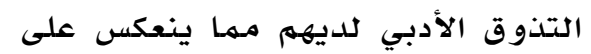

$$
\text { طلابهم. }
$$

r. تفيد القائمين على التعليم الجامعي في تطوير مجالات الذكاء الانفعالي،

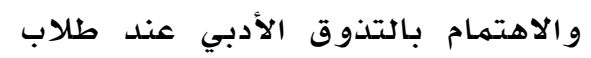
قسم اللغة العربية.

حدود الدراسة

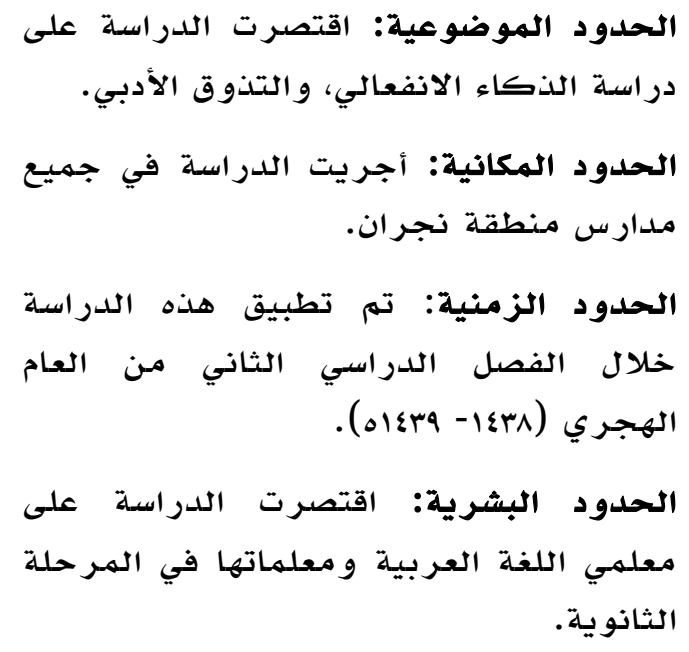

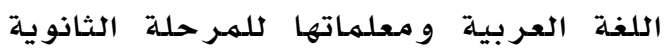
بمنطقة نجران على الوعي بمشاعرهم

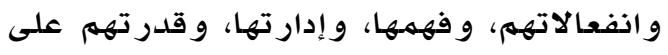

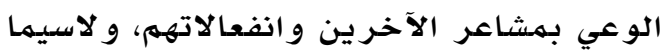

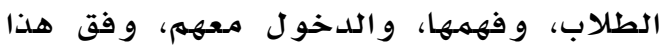

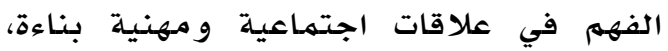


أما في مقياس مهارات التذوق الأدبي فبلغت

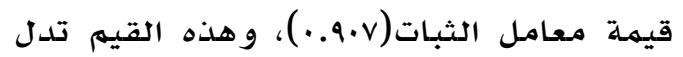

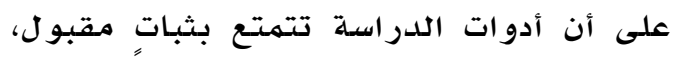
مما يتيح تطبيقه على عينة الدراسة.

\section{الأساليب الإحصائية}

تم استخدام الأساليب الإحصائية التالية: 1. التكرارات والنسب المئوية لتحديد توزيع عينة الدراسة حسب المتغيرات.

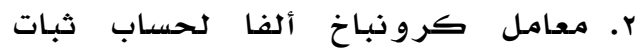
الاتساق الداخلي لأدوات الدراسة. r. المتوسطات الحسابية والانحر افات المعيارية للفقرات و المجالات.

ء. تحليل التباين للكشف عن الفروق بين

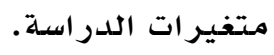

ه. معامل ارتباط بيرسون لكثف عن

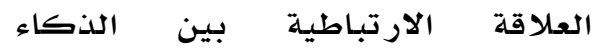
الانفعالي ومهار ات التذوق الأدبي. 1. تحليل الانحدار للكثف عن أثر الذكاء الانفعالي على مهار ات التذوق الأدبي.

نتائج الدر اسة ومناقشتها

السؤال الأول: ما مستوى الذكاء الانفعالي لدى معلمي اللغة العربية ومعلماتها للمرحلة

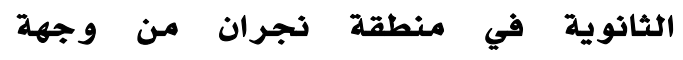

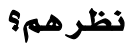

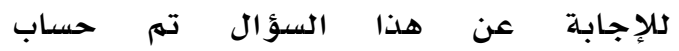
المتوسطات الحسابية والانحر افات المعيارية والرتب لجميع الأبعادة، والأداة الكلية،

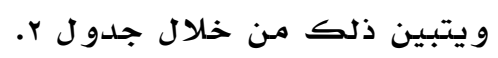

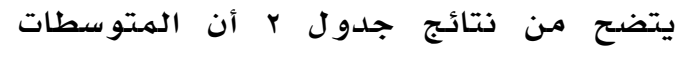
الحسابية لفقرات مستوى الذكاء الانفعالي

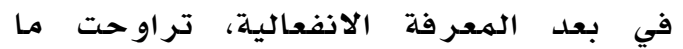

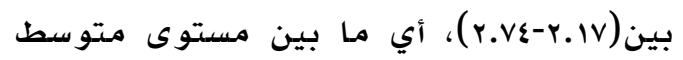

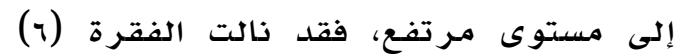

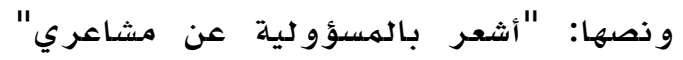

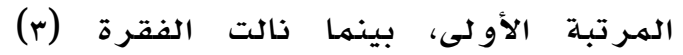
و نصها: "تساعدني النفعالاتي على اتخاذ التهرة
أدوات الدراسة وخصائصها السيكومترية من أجل بناء أدوات الدراسة تم الرجوع إلى الى الدوري

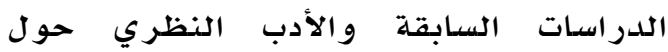

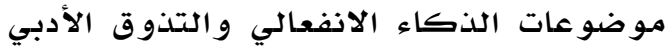

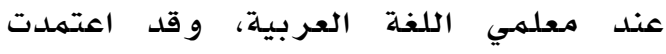

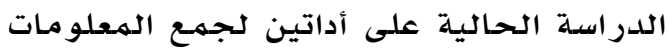

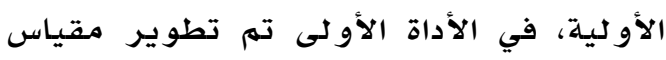
للذكاء الانفعالي، يحتوي على أربعة الادية أبعاد

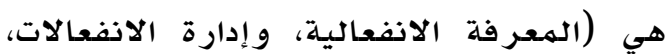

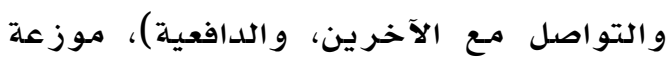

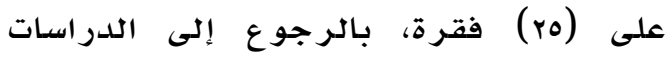

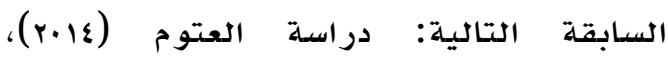

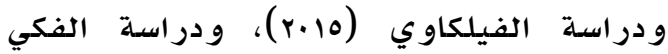

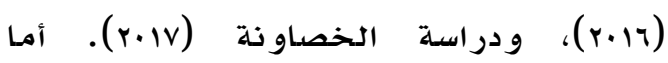

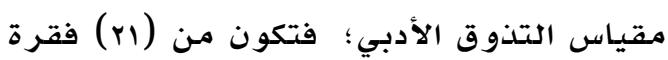

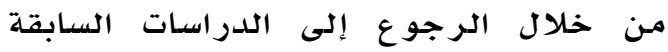

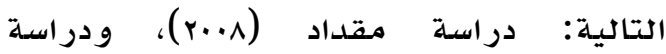

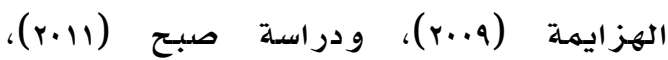
ودراسة الشديفات (r.r.r).

صدق الأداة: للتحقق من صدق أدوات

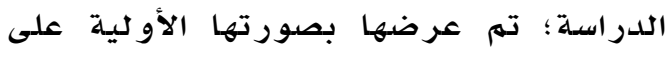

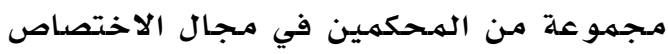

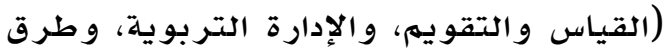

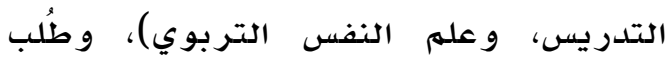

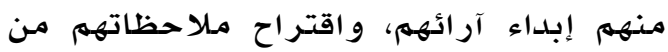

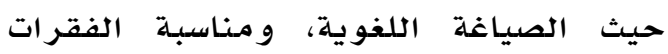

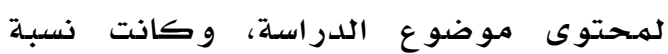

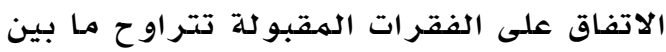

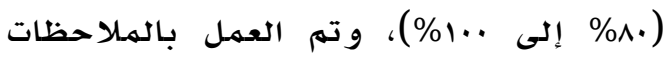
المقترحة، والتي تضمنت حذف ثلاث فقرات

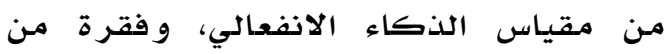
مقياس التذوق الأدبي، و تعديل الفقرات الاتفعال التي أشار إليها المحكمون.

ثبات الأداة: للتحقق من ثبات أدوات الدراسة،

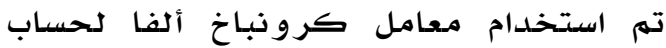

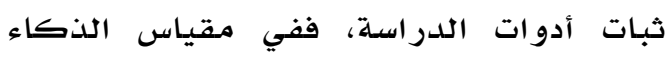

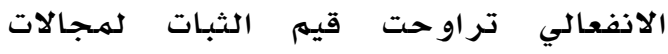

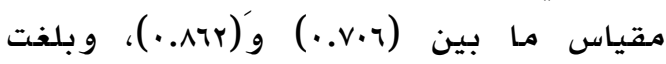
قيمة معامل الثبات للمقياس ككل (901.، (.)، 


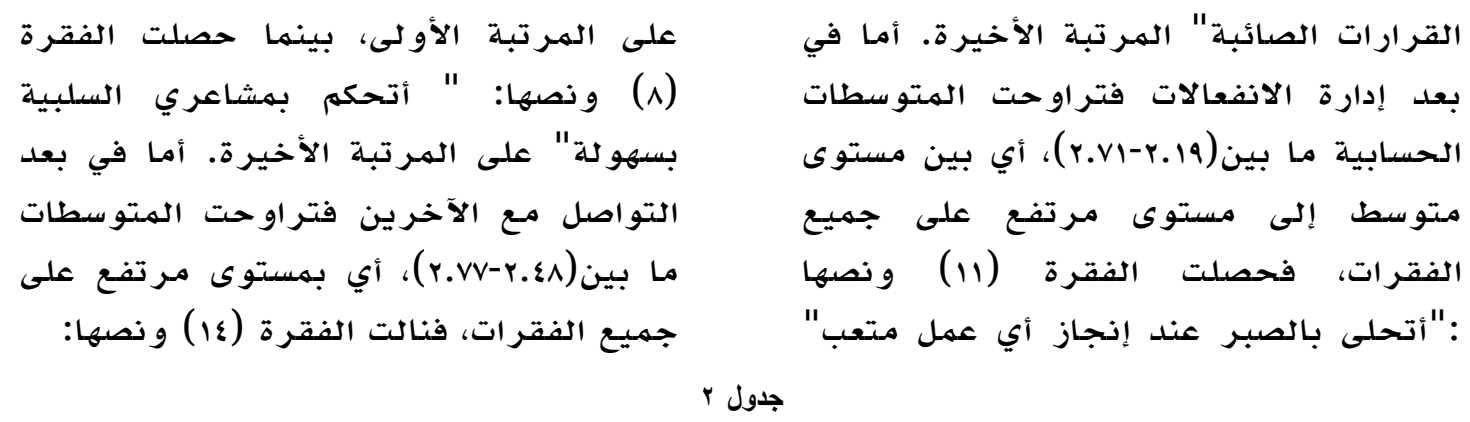

المتوسطات الحسابية والانحرافات المعيارية والرتب لمستوى الذكاء الانفعالي لاى معلمي ومعلمات اللغة العربية للمرحلة الثانوية

في منطقة نجران على جميع الأبعاد، والأداة الكلية

\begin{tabular}{|c|c|c|c|c|c|}
\hline 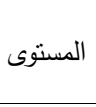 & 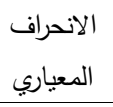 & المنوسط & الفقرات & s & الرتبة \\
\hline & & & البعد الأول: المعرفة الانفعالية & & \\
\hline متوسط & $.00 \mathrm{r}$ & r.OV & أستطيع استيعاب مشاعر طلابي. & 1 & $\varepsilon$ \\
\hline مرتقع & .007 & r. $\_9$ & أعبر عن مشاعري نحو الأحداث بسهولة. & r & $\circ$ \\
\hline متوسط &. .799 & r.lv & تساعدني انفعالاتي على اتخاذ القرارات الصائبة. & r & v \\
\hline 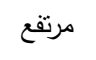 & $.7 \leq \varepsilon$ & r.乏 & أستطيع أن أفهم انفعالاتي المتتاقضة. & $\varepsilon$ & 1 \\
\hline 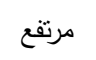 &. $.0 \mathrm{rV}$ & r.TV & لدي القدرة على تحديد جوانب القوة والضعف في ذاتي. & $\circ$ & r \\
\hline 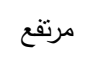 & .019 & r.V $\varepsilon$ & أشعر بالمسؤولية عن مشاعري. & 1 & 1 \\
\hline 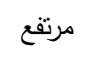 & .010 & $r .70$ & اقدر انفعالاتي وعواطفي تقديراً واقعيا. & v & $r$ \\
\hline 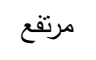 & .ror & r.or & المنوسط العام لبعد المعرفة الانفعالية. & & \\
\hline 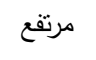 &.$r$ tret & Y. $\leqslant \uparrow$ & البعد الثاني: إدارة الانفعالات & & \\
\hline 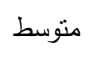 &. .774 & $r .19$ & أتحكم بمشاعري السلبية بسهولة. & $\wedge$ & $\varepsilon$ \\
\hline 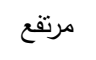 &. .079 & $r . \varepsilon r$ & أستطيع استدعاء الانفعالات التي نساعدني في التعبير عن ذاتي. & 9 & r \\
\hline 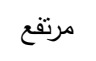 & 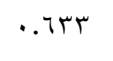 & $r . \varepsilon r$ & أستطيع احتواء مشاعر الإجهاد التي تعوق أداء أعمالي. & 1. & $r$ \\
\hline 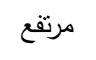 & $\cdot . \leqslant 9 \leqslant$ & r.VI & أتحلى بالصبر عند إنجاز أي عمل متعب. & 11 & 1 \\
\hline 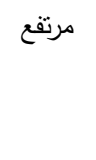 & $. .0 \times 1$ & $r .00$ & أستطيع ربط مشاعري بما أفكر فيه. البعد الثالث: البعام البعد إدارة الانفعالات. & ir & r \\
\hline 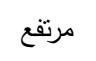 &..$\varepsilon 9 \wedge$ & r.v & لدي القدرة على الثأثير الإيجابي على طلابي • & ir & $r$ \\
\hline 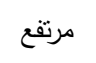 &..$\leqslant 10$ & r.VV & 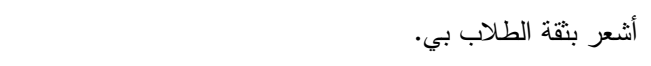 & $1 \leq$ & 1 \\
\hline 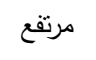 & $\cdot . T \leqslant V$ & r.01 & أهنت بمشكلات طلابي. & 10 & ○ \\
\hline 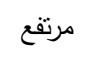 & $.0 \leq 0$ & $r .7$ & أنقبل النقد من طلابي. & 17 & $\varepsilon$ \\
\hline 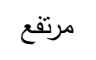 & .7 .0 & r.or & أقيم علاقات شخصية ناجحة مع طلابي. & iv & 7 \\
\hline 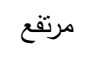 & $.0 \leq r$ & $r .7 \uparrow$ & أستطيع إيجاد بيئة صفية مناسبة في التعامل مع طلابي. & 11 & r \\
\hline 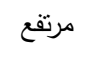 & .0 .9 & r.VT & أستطيع فهم تعبيرات لغة الجسد الصادرة من طلابي & 19 & r \\
\hline 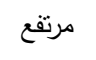 & $\cdot .7 \cdot 7$ & $r . \varepsilon \wedge$ & أستطيع دفع طلابي لإقامة علاقات ناجحة. & r. & V \\
\hline 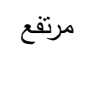 &.$r q \vee$ & T.7ะ & 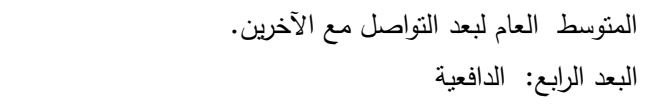 & & \\
\hline 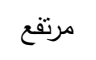 &. .011 & r.乏 & أواجه العقبات الني تمنعني عن تحقيق أهدافي. & r) & ○ \\
\hline 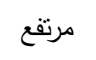 &. .09 & $r .01$ & أفضل إنجاز الأعمال التي تتطلب مهارة. & rt & $\varepsilon$ \\
\hline 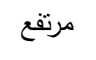 &. .200 & r.Al & يزداد تقديري لذاتي عندما أنغلب على عاده سيئة. & rt & $r$ \\
\hline 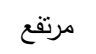 &. $.0 Y r$ & T.VY & أسعى دومًا لأكون من المتميزين في أدائي التدريسي. & $r \leq$ & r \\
\hline 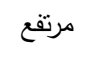 & $\cdot r$ & r.9r & أسعد بتحقيق طلابي لمراكز متقدمة. & ro & 1 \\
\hline 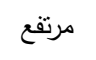 & $\cdot r$ rq & $r .7 \uparrow$ & المتوسط العام لبعد الدافعية. & & \\
\hline 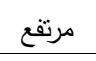 & $\cdot .+7$ & r.01 & المتوسط العام للأداة ككل. & & \\
\hline
\end{tabular}


فاينسنت (Vincent, 2003) حين ذكرت أن (1)

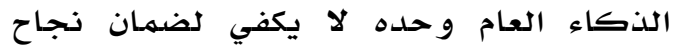

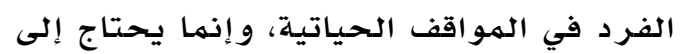

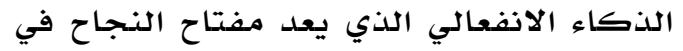

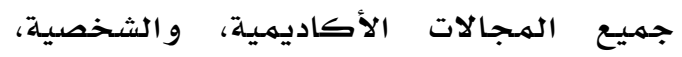

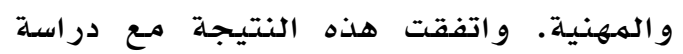

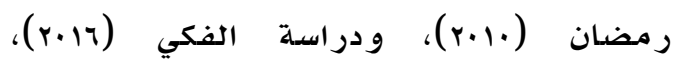

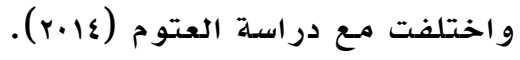

السؤال الثاني: هل توجد فروق دالة إحصائيًا بين آراء معلمي اللغة العربية ومعلماتهاتها

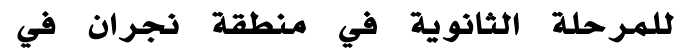

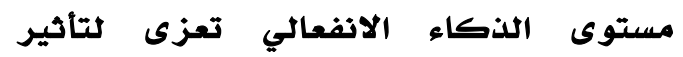
متغيرات الجنس، والمؤهل العلمي، وسنوات

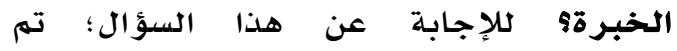

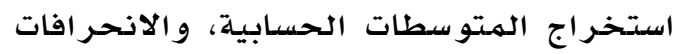

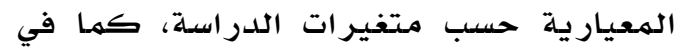
جدو ل م.

يتبين من جدول

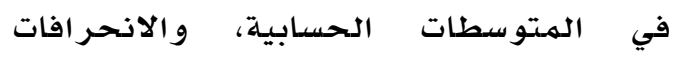

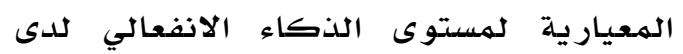

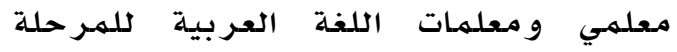

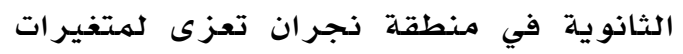

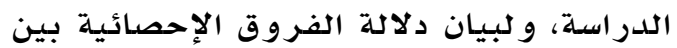
المتوسطات الحسابية تم استخدام تحليل التباين الثلاثي كما في جدو ل ع.
"أثعر بثقة الطلاب بي" المرتبة الأولى،

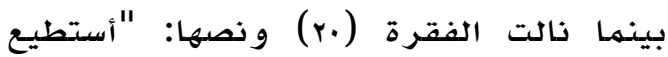

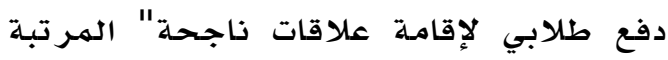

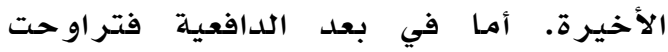

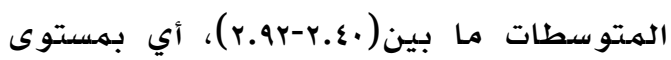
مرتفع على جميع الفقرات، فحصلت الفقرة

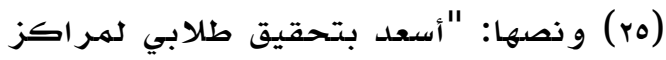

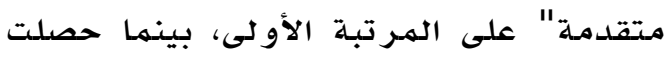

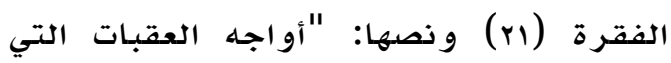

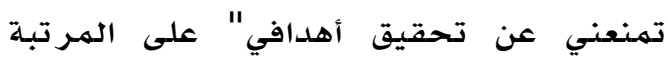

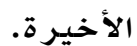

كما يتضح من النتائج أن المتوسطات الحسابية على جميع أبعاد الذكاء الانفعالي

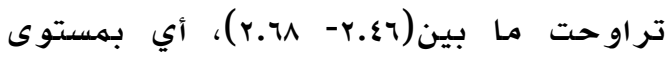

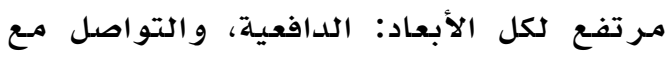

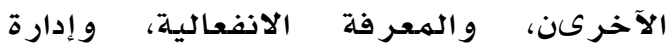

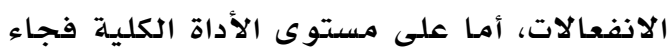
مستوى الذكاء الانفعالي لدى الدى المعلمين

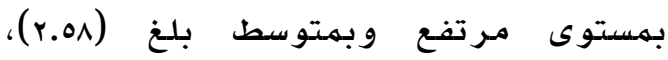

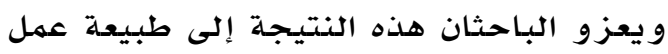

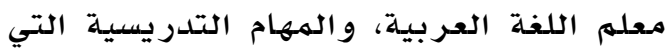
يقوم بها، وضرورة توافر الذكاء الانفعالي عنده، لما له من دور له في نجاحه بحياته

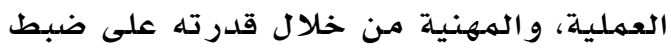
انفعالاته، و تفكيره، و فهمهـ لانفعالات الآخر ين هنهين الذين يتعامل معهم، مـما يساعده على النجاح

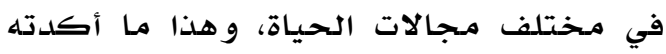

المتوسطات الحسابية، والانحرافات المعيارية لمستوى الذكاء الانفعالي لدى معلمي ومعلمات اللغة العربية للمرحلة الثانوية في منطقة نجران حسب متغيرات الاراسة

\begin{tabular}{|c|c|c|c|c|}
\hline الانحراف المعياري & المتوسط الحسابي & العدد & المستويات & المتغير المستقل \\
\hline . ror & T.O & r & ذكر & \\
\hline.$r \Lambda \Lambda$ & $r .09$ & Vr & انثى & الجسل \\
\hline .rTA & r.00 & VT & بكالوريوس & \\
\hline. YO & T.TV & rr & بكالوريوس+ دبلوم & المؤهل العلمي \\
\hline GTH & r.OV & 11 & ماجستير & \\
\hline.$r 99$ & $r . \leqslant T$ & $1 \varepsilon$ & اقل من r سنوات & \\
\hline. .195 & r.tr & ro & من r إلى 7 سنوات & سنوات الخبرة \\
\hline מוr. & r.09 & 74 & أكثر من 7 سنوات & \\
\hline
\end{tabular}


جدول

نتائج تحليل التباين الثلاثي لمستوى الذكاء الانفعالي لاى معلمي ومعلمات اللغة العربية للمرحلة الثانوية في منطقة نجران حسب

متغيرات الاراسة مئة ومعات

\begin{tabular}{|c|c|c|c|c|c|}
\hline مستوى الدلالة & قيمة ف & متوسط المربعات & درجات الحرية & مجموع المربعات & مجموع المربعات \\
\hline. ro & $1 . r \leq 1$ & $\because M r$ & 1 & $\because I Y Y$ & الجنس \\
\hline$\cdot r 10$ & $1.07 r$ & $\because 1 \leq r$ & r & $\because r \wedge 0$ & المؤهل العلمي \\
\hline \multirow[t]{3}{*}{.178} & I.AKr & .177 & r & תTr & سنوات الخبرة \\
\hline & & $\ldots 991$ & 99 & q.. TV & الخطأ \\
\hline & & & 1.0 & $\vee \cdot \wedge . \wedge \cdot T$ & المجموع \\
\hline
\end{tabular}

كمور والجندي (\&) (r). أما متغير الخبرة

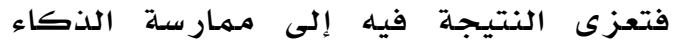

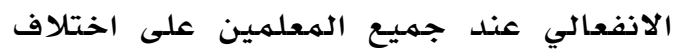

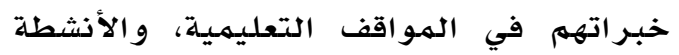

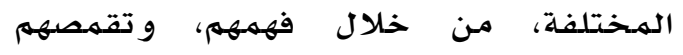

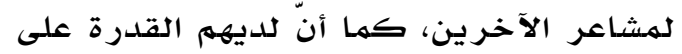

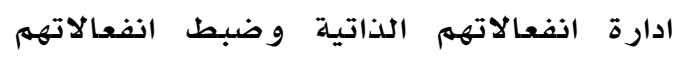

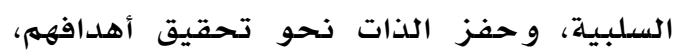

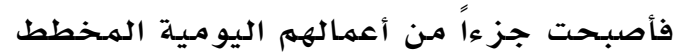

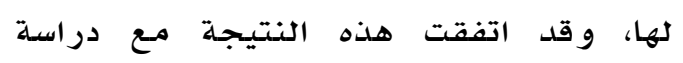

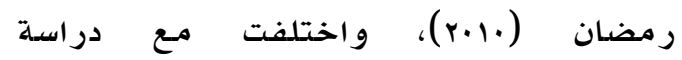

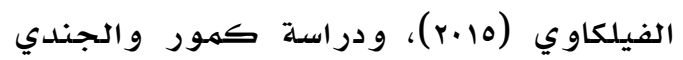

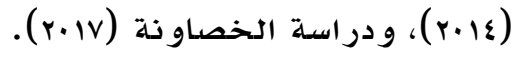

السؤال الثالث: ما مستوى مهارات التذوق الأدبي لدى معلمي، اللغة العربية ومعلماتها للمرحلة الثانوية في منطقة نجران التي التيل يراعونها في تدريسهم للطلبة من وجهية نظرهمو للإجابة عن هذا السؤال تم حسـاب

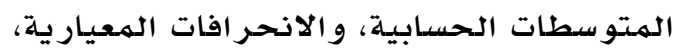

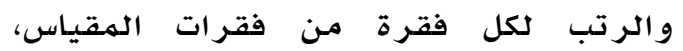

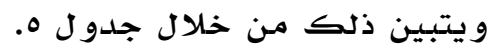

يتضح من نتائج جدول ه أن المتوسطات

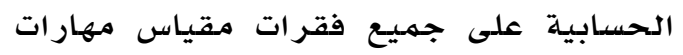
التذوق الأدبي تراوحت مـا بين (•ع.ب-r.r.r)،

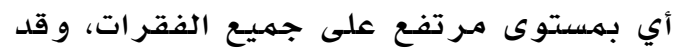

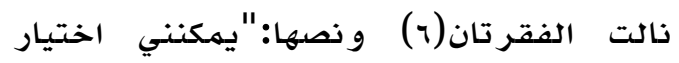
بيت معبر عن أحاسيس الشاعر" ورقم (v) ونصها:
يلاحظ من جدول ع عدم وجود فروق دالة

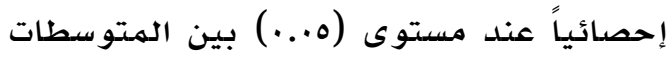

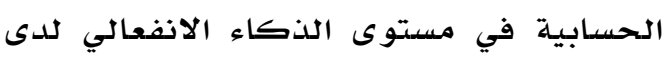

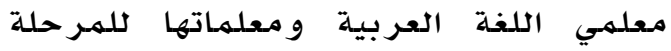
الثانوية تعزى لهتغير ات الجنس، و والمؤهل

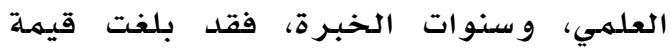

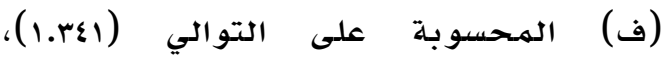

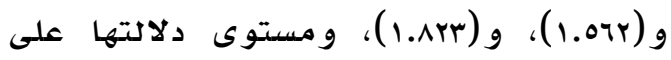

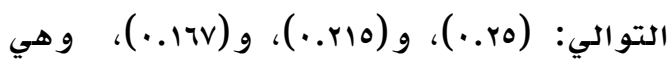

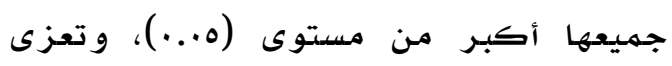
هذه النتيجة في متغير الجنس إلى تشابه

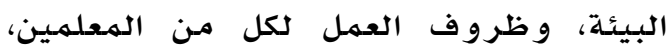
و المعلمات في مسمارستهم للذكاء الانفعالي في حياتهم الوظيفية اليومية، من خلاهل

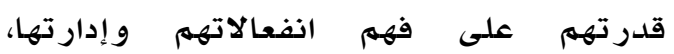
وقدرتهم على التعبير عنها، فيؤدي ذلك إلى الى

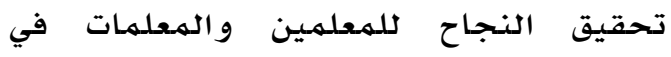
العهل، وتحقيق الرضدا الوظيفي. و وقد اتفقت

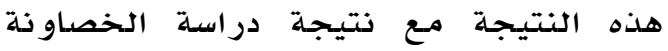

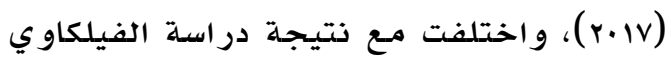

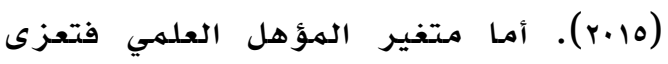

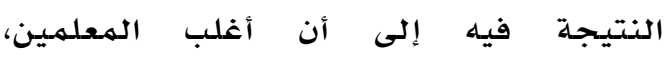

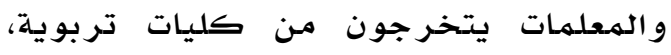

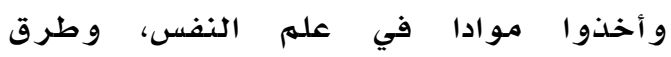
التدريس، فأصبحت لديهم القدرة علد الدى الوعي بالانفعالات والمشاعر والتعبير عن الحاجات

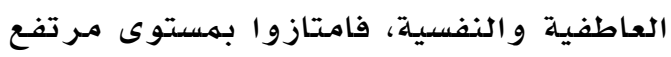
من الذكاء العاطفي، وبقدرة على تنظيه

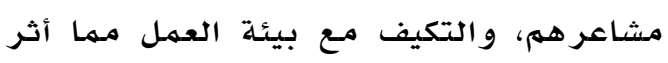
عليهم في أدائهم الوظيفي، وقد اتفقت هذه مدئ

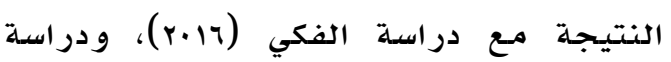

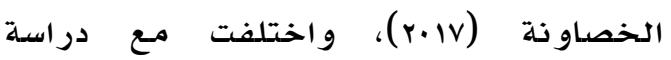


جدول

المتوسطات الحسابية، والانحرافات المعيارية، والرتب لمستوى مهارات التذوق الأدبي لاى معلمي ومعلمات اللغة العربية للمرحلة الثانوية في منطقة نجران من وجه نظرهم على جميع الفقرات، والأداة الكلية

\begin{tabular}{|c|c|c|c|c|c|}
\hline 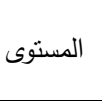 & المعباري & 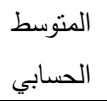 & 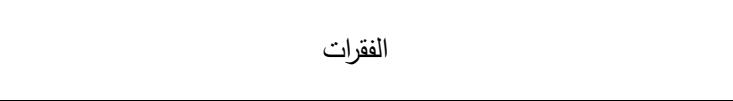 & 5 & الرتبة \\
\hline مرتفع &. .719 & T.00 & أستطيع تحديد وحدة الموضوع في النص الأدبي. & 1 & 9 \\
\hline 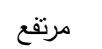 &. .071 & r.70 & أدرك أهمية الكلمة التعبيرية في النص الأدبي. & r & ○ \\
\hline مرتفع & $.0 Y_{1}$ & $r .79$ & أستطيع الكثف عن العواطف المنضمنة في النص. & r & r \\
\hline 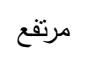 &. $.0 \mathrm{Vl}$ & r.०0 & أنمكن من استتناج العلاقة بين العواطف، وأفكار النصوص، ومعانيها. & $\varepsilon$ & $1 \cdot$ \\
\hline 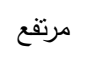 & .0 .9 & r.Vr & أدرك قيمة العواطف في النصوص الأدبية. & $\circ$ & r \\
\hline مرتفع & .000 & r.Vr & يمكنني اختيار بيت معبر عن أحاسيس الثاعر. & 7 & 1 \\
\hline مرتفع & .0 .0 & r.Vr & أسنطيع تحديد الصور الجمالية في النصوص الأدبية. & v & 1 \\
\hline مرتفع &. .011 & $r .00$ & أستطيع تحديد نوع الصور البيانية التي تتضمنها النصوص الأدبية. & $\wedge$ & 1. \\
\hline مرتفع &. $.0 \mathrm{Vr}$ & r. $\varepsilon q$ & أتمكن من التمييز بين مكونات الصور في النص. & 9 & r \\
\hline 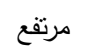 &. $.0 \mathrm{Vr}$ & r.o & أدرك الأغراض البلاغية من الصور البيانية والأساليب. & 1. & ir \\
\hline 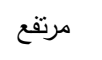 & $.0 \% 0$ & r.07 & أستطيع بيان قيمة الصور الأدبية في إبراز الفكرة. & 11 & $v$ \\
\hline 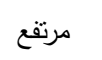 &. .74 & r. $\leqslant \uparrow$ & لاي القدرة على تحديد مدى انسجام العواطف مع صور النصوص الأدبية. & ir & 10 \\
\hline 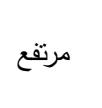 & .70 & T. $\leqslant 0$ & صورة) أستطيع بيان أثر كل جزئية من جزئيات الصياغة (كلمة، أو تركيباً، أو & ir & 17 \\
\hline مرتقع &. .011 & $r . \varepsilon \varepsilon$ & أتنين مدى مهارة الأديب في تجسيد المعنويات، وفهم الرمز ، وتفسيره. & $1 \leqslant$ & iv \\
\hline مرتفع & $\cdot .0 \wedge \mathrm{V}$ & r.07 & استخدم الصفات التي يصف الأديب بها نفسه، أو يصف بها الآخرين. & 10 & V \\
\hline 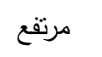 & $.0 \leq 1$ & r.Tr & 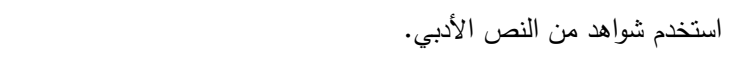 & 17 & 1 \\
\hline 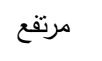 & $\cdot 7 \cdot 7$ & r.01 & أرتب الأبيات والقصائد حسب جودتها، أو وضوحها، أو صدقها. & iv & 11 \\
\hline مرتفع &. .019 & $r . \leqslant V$ & أستطيع الموازنة بين جماليات النصوص أو الأبيات في موضوع واحد. & 11 & $1 \varepsilon$ \\
\hline مرتفع & $\cdot . T \wedge V$ & r.乏 & أمتلك حساسية لوزن الأبيات وإدراك ما فيها من نشاز موسيقي. & 19 & 11 \\
\hline مرتفع & $.7 \leq \varepsilon$ & r.乏 & أكتثف الحشو في الأبيات أو النص. & r. & 11 \\
\hline مرتفع & $.0 \leqslant r$ & r.TA & أدرك أثر القافية في جمال الأبيات. & r) & $\varepsilon$ \\
\hline مرتفع & ..हार & $r .07$ & الأداة ككل & & \\
\hline
\end{tabular}

مواطن الجمال من خلال معايشـة القارئ، أو

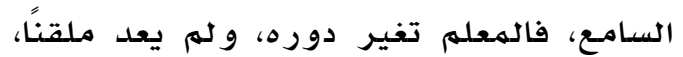
فيظهر دوره في تنمية التذوق الأدبي لدى لدى دونى طلبته من خلال إيمانه بأن كل طالب لدية القدرة على التذوق الأدبي، و أنه يهكن تدريبه

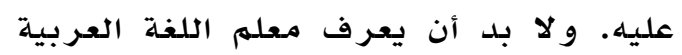

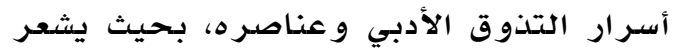

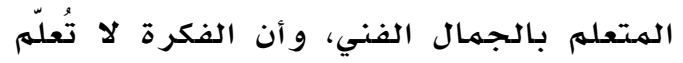
في إطار العهل الأدبي إلا من خلالال وحدة

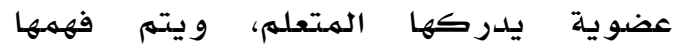
و تذوقها في جو نفسي رائع. وينبغي على أنى الهعلهم أن تكون لدية القدرة على تبين أهم

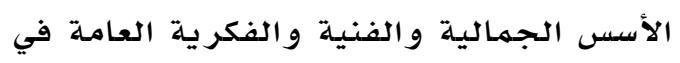

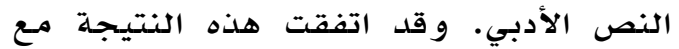

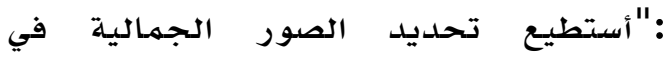

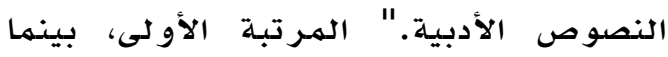

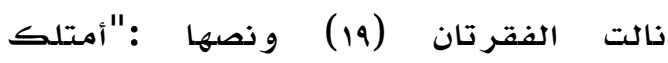

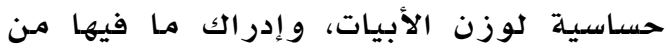

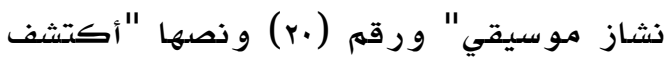

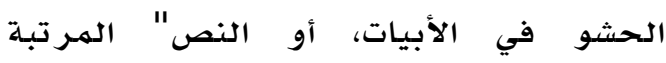
الأخيرة. أما على مستوى الأداة الكلية فقد الهد

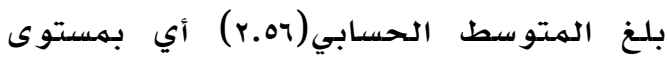

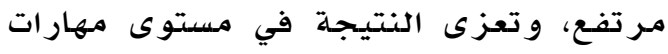
التذوق الأدبي لدى معلى معلمي اللغة العربية بالدرجة الأولى إلى تخصص الهعلىمين في الهي

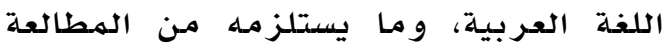

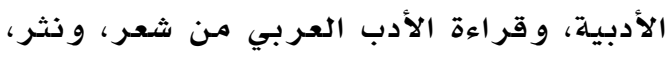

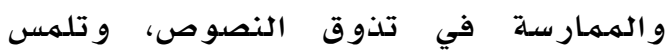


الحسابية، تم استخدام تحليل التباين الثلاثي

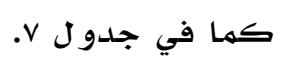

يشير جدول V إلى عدم وجود فروق دالة

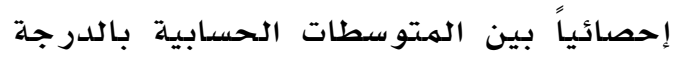

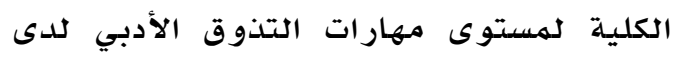

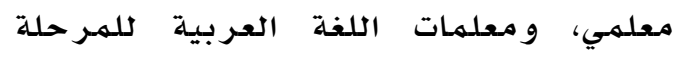

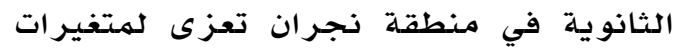

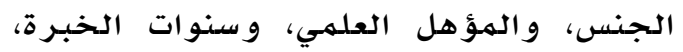

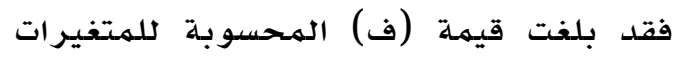

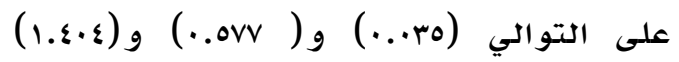

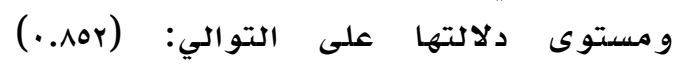

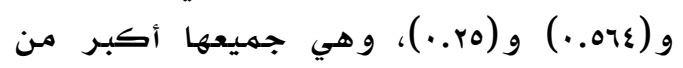
مستوى (.0..). (.0).

ففي متغير الجنس، فقد أظهرت النتائج عدم

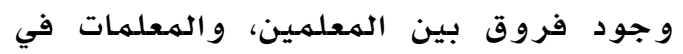

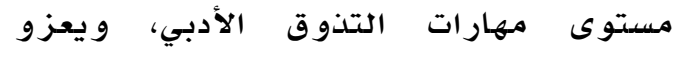

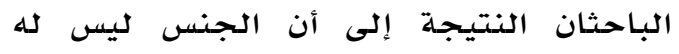

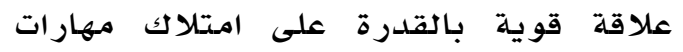

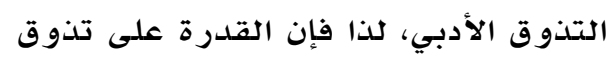

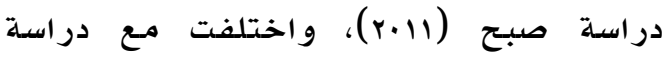

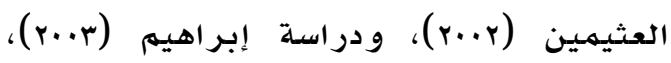

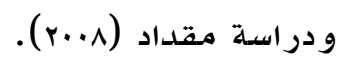

السؤال الرابع: هل توجد فروق دالة إحصائيًا

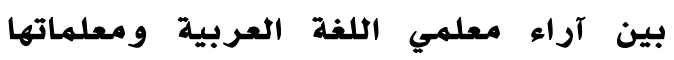

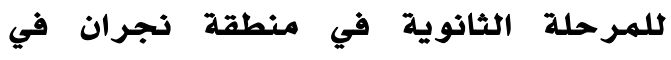
مستوى مهارات التذوق الأدبي تعزى لتأثير

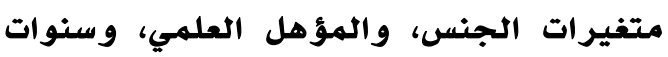

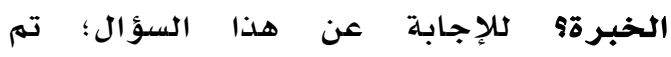

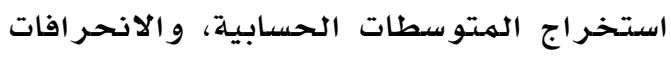

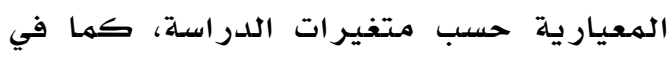

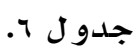

يتبين من جدول 1 أن هناك تبايناً ظاهرياً في

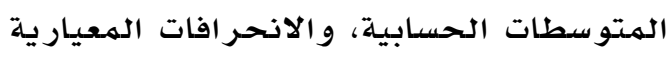

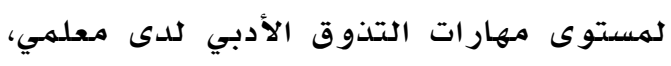

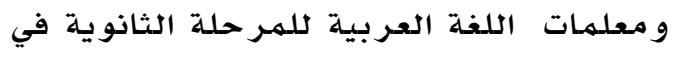

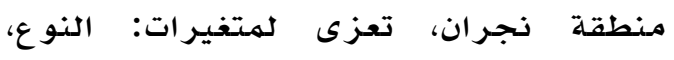

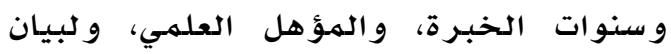

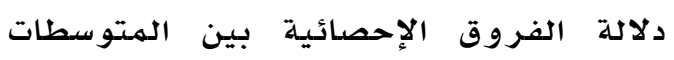

جدول 1

المتوسطات الحسابية والانحرافات المعيارية لتحديد مستوى مهارات التنوق الأببي لاى معلمي، ومعلمات اللغة العربية للمرحلة الثانوية في منطقة نجران حسب متغيرات الاراسة الكابة

\begin{tabular}{|c|c|c|c|c|}
\hline الانحراف المعياري & المتوسط الحسابي & العدد & المستويات & المتغير المستقل \\
\hline . TVT & $T .00$ & זr & ذكر & \multirow{2}{*}{ الجنس } \\
\hline$\cdot . \leqslant r V$ & T.07 & $V Y$ & انثى & \\
\hline$\cdot . \leqslant \leq 9$ & r.or & $V T$ & بكالوريوس & \multirow{4}{*}{ المؤهل العلمي } \\
\hline תT & $r .09$ & rr & بكالوريوس+ دبلوم & \\
\hline$\because r \cdot \wedge$ & T.70 & 11 & ماجستير & \\
\hline. .499 & r.rq & $1 \leq$ & اقل من r سنوات & \\
\hline ת & r.07 & ro & من r إلى 7 سنوات & \multirow[t]{2}{*}{ سنوات الخبرة } \\
\hline . & $r .09$ & דו & أكثر من 7 سنوات & \\
\hline
\end{tabular}

\section{جدول}

نتائج تحليل التباين الثلاثي لمستوى مهارات التذوق الأدبي لاى معلمي ومعلمات اللغة العربية للمرحلة الثانوية في منطقة نجران

حسب متغيرات الاراسة

\begin{tabular}{|c|c|c|c|c|c|}
\hline مستوى الدلالة & قيمة ف & متوسط المربعات & درجات الحرية & مجموع المربعات & مصدر النباين \\
\hline . . & ...ro & $\ldots .4$ & 1 & $\ldots$. & الجنس \\
\hline $.07 \varepsilon$ & $.0 \mathrm{VV}$ & $\ldots 99$ & r &. .199 & سنوات الخبرة \\
\hline \multirow[t]{3}{*}{.ro } & $1 . \varepsilon \cdot \varepsilon$ & $. r \leqslant r$ & r & . . ¿یर & المؤهل العلمي \\
\hline & &..$M Y$ & 99 & $1 v . . r q$ & الخطأ \\
\hline & & & 1.0 & V.T.AVT & المجموع \\
\hline
\end{tabular}


الأدبي، كما قد يكون للدورات التدريبية المختتلفة التي يتلقاها المعلمون على اختّلاف

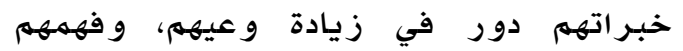

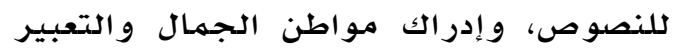
و أثره في النفس، فلا يكتفون فقط بالشرح

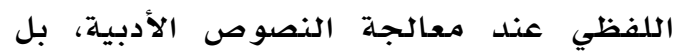

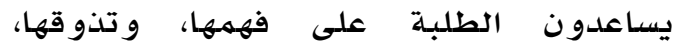
و تحليها، و بالتالي ينعكس أثره على قدر تهم في التذوق الأدبي. وقد اختلفت هذه النتيجة

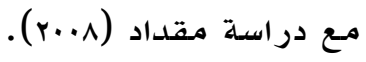

السؤال الخامس: هل يمكن التنبؤ بمستوى

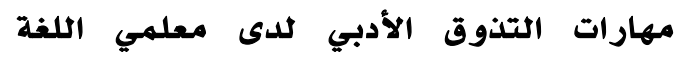

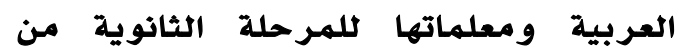
خلال الذكاء الانفعالي، ومكوناته الفرعية؟ لإجابة عن هذا السؤال تم استخدام أسلوب تحليل الانحدار كما في جدول ل ^.

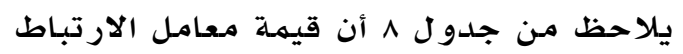

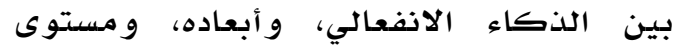

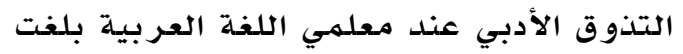

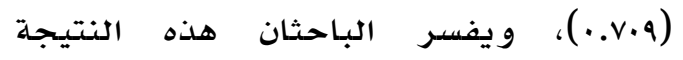

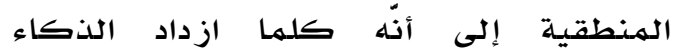

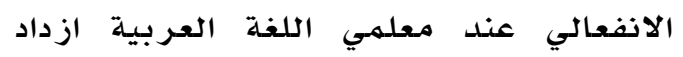
مستوى مهار اتهم في التذوق الأدبي للنصوص

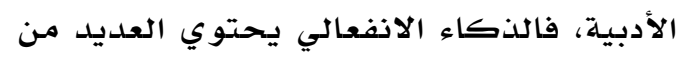

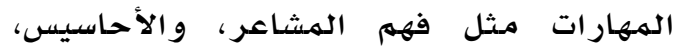

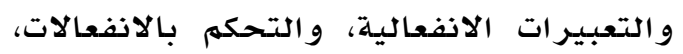

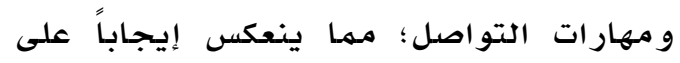

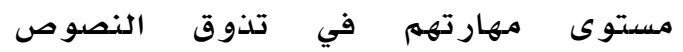

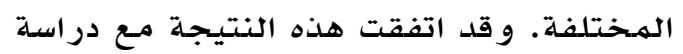

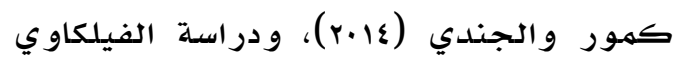

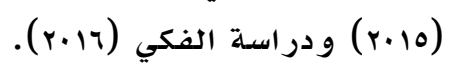

النصوص الأدبية لن تتغير بتغير الجنس نتيجة تشـابه الظروف لكل من المعلمين،

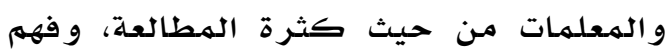
الهعاني العميقة في النص الأدبي، والإقبال

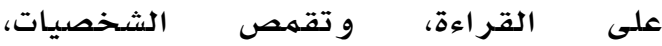

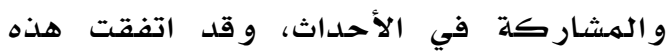

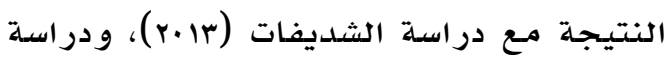

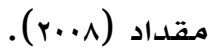

أما متغير الهؤهل العلهي، فأظهرت نتائجها عدم وجود فروق بين المعلمين، والمعلمات مهات حسب مؤهلهم العلمي في مستوى مهار ات

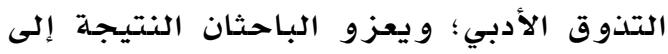

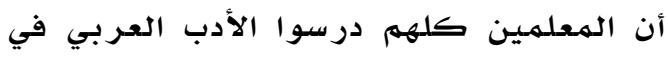

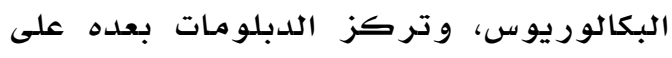

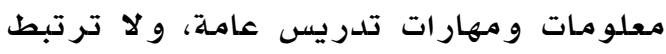

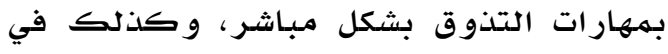

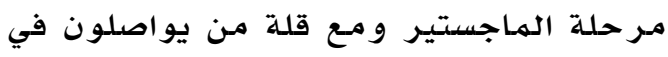

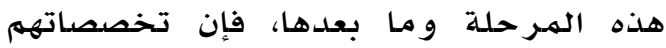

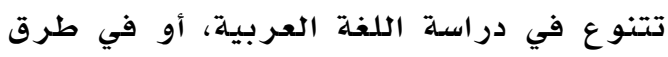

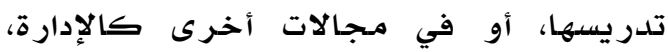

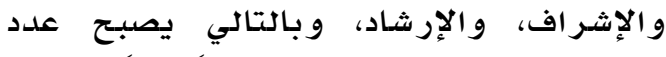
دارسي الأدب العربي فيها قليلاً جداً مقارنة بغيره من التخصصدات، وهو ما يظهر تقارب

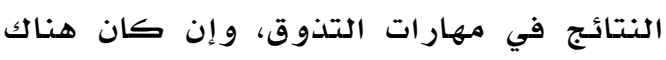
تفاوت في التأهيل العلمي. ووقد اختلفت هذهاري

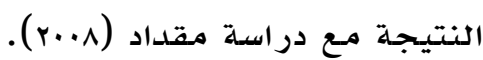

أما متغير الخبرة، فأظهرت النتائج فيه عدم وجود فروق بين المعلمين والمعلمـات حسب آبـ خبرتهم في مستوى مهارات التدوق فوف الأدبي؛ ويعزو الباحثان النتيـجة إلى إقبال المعلمينين

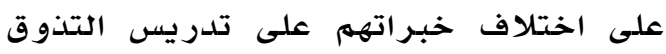

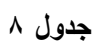

تحليل الانحدار لأثر الذكاء الأفعالي على التذوق الأدبي

\begin{tabular}{|c|c|c|c|c|c|c|c|}
\hline مستوى الدلالة & المحسوبة t قيمة & Beta & الخطناً & B & معامل التحديد & معامل & الذكاء الانفعالي وأبعاده \\
\hline$\cdot, \cdots$ & 0.979 & $0 . v$ & $\cdots 99$ & $.09 \varepsilon$ & & & المعرفة الانفعالية \\
\hline$\cdot, \cdots$ & $7 . . \leq r$ & 014 & $\cdots 91$ & .00 & & & إدارة الانفعالات \\
\hline$\cdot, \cdots$ & N.ro & דזד & $\cdots \vee \vee q$ & .97 & $.0 . r$ & $\because v \cdot q$ & التواصل مع الآخرين \\
\hline$\cdot, \ldots$ & 1.99 & אדצד. &. $.9 r$ & י & & & 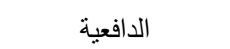 \\
\hline$\cdot, \cdots$ & 9.711 & .79 & $\because 99$ & .94 & & & الذكاء الانفعالي ككل \\
\hline
\end{tabular}


الاستر اتيجيات الهناسبة لتنمية مهار ات

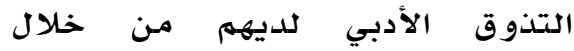
النصوص التطبيقية، وربطها بالذهاء الانفعالي و مهار اته.

r. زيادة اهتمام كليات التربية، و كليات

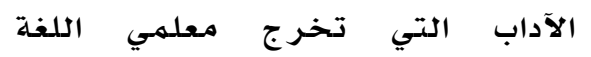

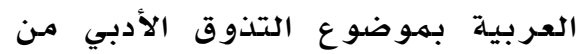

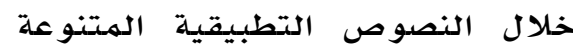

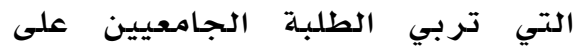

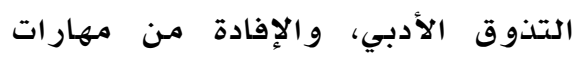
الذكاء الانفعالي في ذلك. مقتر حات الدراسة ا. دراسـة عن فاعلية برنامـج تدريبي قائم

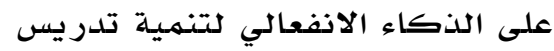
مهارات التذوق الأدبي لدى معلمي اللغة العربية.

r. دراسات عن علاقة الذكاء الانفعالي للمعلمين بأدائهم التدريسي لبعض البه

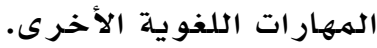

r. دراسات عن علاقة الذكاء الانفعالي للطلاب باكتسابهم لبعض المرابه المهارات

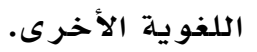
المراجع

\section{References}

إبر اهيه، أحمد (r..r). تقييم الأداء التدريسي للطلاب المعلمين في النصوص احمل الأدبية في ضوء مقومات التذوق الأدبي. مـجلة

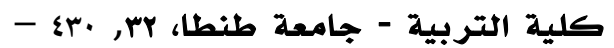

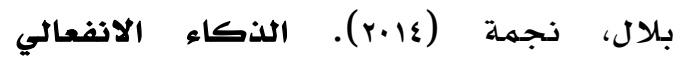
وعلاقته بالثقة بالنفس للى طلاب لابه

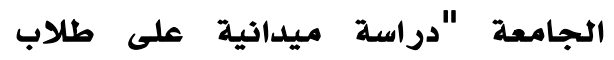

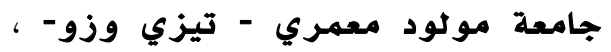
رسالة ماجستير غير منشورة، جمامعة مهودي مو لود معهمري، الجز ائر .

بن غربال، سعيدة (10).

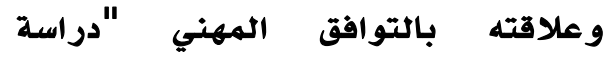

بينها بلغ معامل التحديد (r.0.•)، مها يعني بأن الذكاء الانفعالي، وأبعاده استطاعت أن

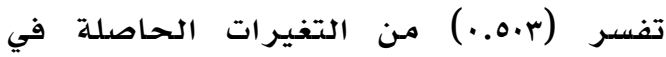
مستوى التذوق الأدبي عند معلمي، ومعلمـات

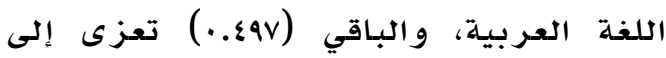

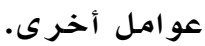
كما يتضسح من النتائج أن الذكاء الانفعالي

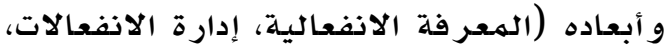

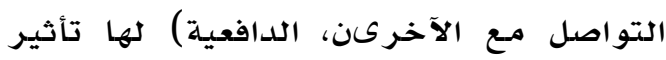

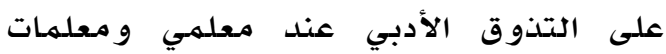

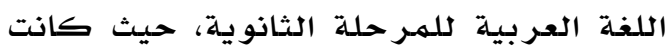

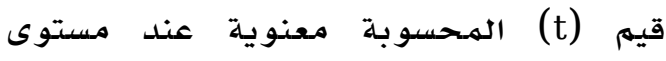

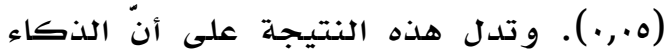
الانفعالي يسهم في التنبؤ بمستوى التذوق التون الأدبي عند المعلمين، مـن خلال قدرة الهدي المعلهم

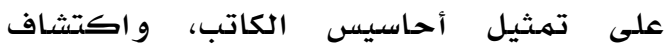
الحالة النفسية التي يعبر عنها في فهمها

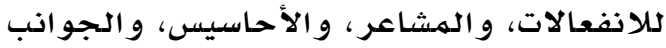
الجمالية في النصوص الأدبية من أجل إتاحة

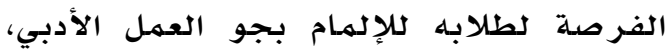

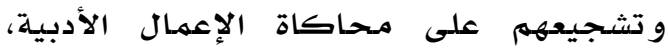

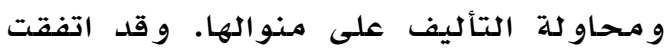

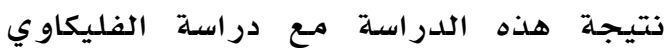

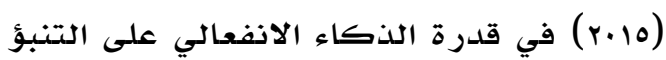
بالتوافق المهني للمعلمين. ويمكن استنتاج معادلة التنبؤ التالية:

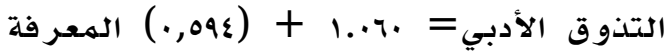
الانفعالية

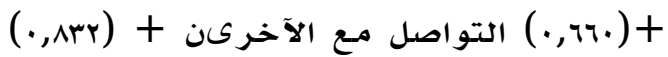
الدافعية + (.rه, •)النكاء الانفعالي ككل. ) التواهل توصيات الدراسة ا. ضرورة إعداد برامـج تدريبية لتنهية

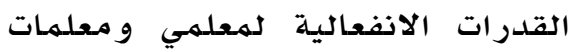
اللغة العربية حتى يتمكنوا مـن الإدارة،

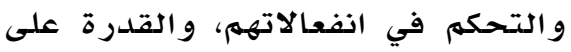
التعامل مـع الآخر ين، و التواصل اصل معهمه. r. ضرورة تلدريب المعلمين وطلبة الجامعات في قسم اللغة العربية على الهين 
الخليفة، حسن (r.r.r). فصول في تدريس

اللغة العر بية. الرياض: مكتبـة الرشد.

الركابي، جودت (ب....). طرق تدريس اللغة

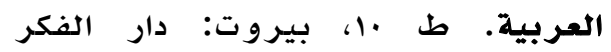

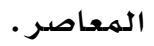

رمضان، حسن نبيل (.1.r). درجة الذكاء

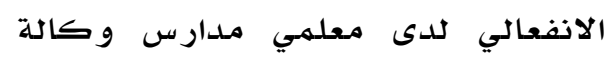
غوث وتشغيل اللاجئين الفلسطينيين في مئي محافظة نابلس. مجلة جامعة القدس

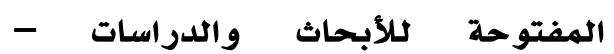

$$
\text { فلسطين،19 ، 0 - vo }
$$

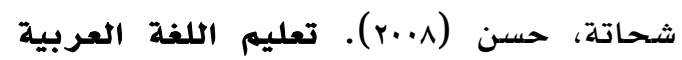
بين النظرية والتطبيق. القاهرة: الدار الهصرية اللبنانية.

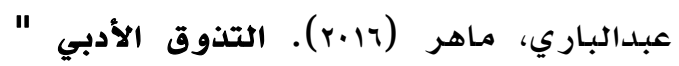

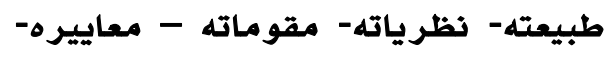
قياسه. عمان: دار الفكر.

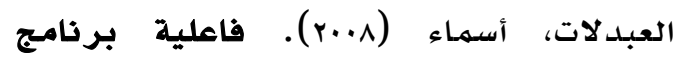
تلدريبي لتنمية الذكاء الانفعالي في التكيف الأكاديمي والاجتماعي وفي الاتجاهات نحو المدرسة للى الطلبة الطية الموهوبين في الأردن. أطروحة دكتوراه، كلية الدراسات العليا، عمان، الأردن.

عبدالعظيم، سـلامـة ؛ و عبدالعيظم، طه (7..r).

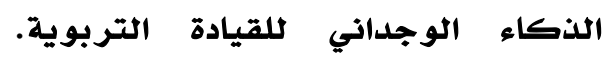

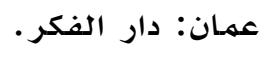

العتوم، نداء (عا.r). مستوى الذكاء العاطفي للى معلمات الصفوف الثلادة الأولى في محافظة جرش وعلاتهته باتجاهاتهن نحو مهنة التدريس. رسالة ماجستير

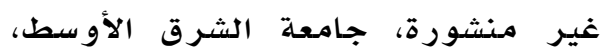

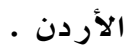

العثيمين، لطيفة (r.r). واقع ممارسة

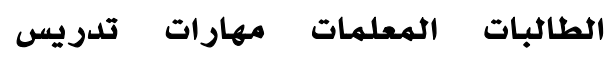
النصوص الأدبية في المرحلة المتوسطة بالعاصمة المقدسة. رسالة ماجستير
ميدانية على عينة من أساتذة جامعة

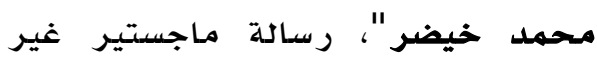

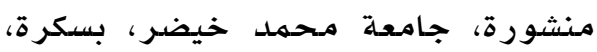

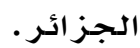

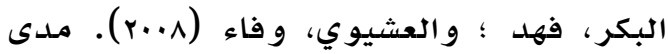

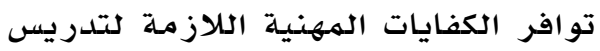

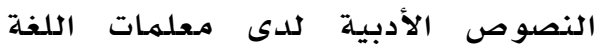

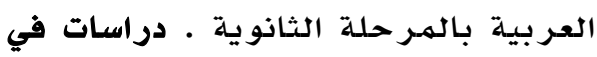
المناهج وطرق التدريس، سبا، 117 $.1 \leqslant \wedge$

سعيد، سعاد (r.v.). الذكاء الانفعالي وسيكولوجية الطاقة اللامحدودة. إربد: دار عالم الكتب الحديث.

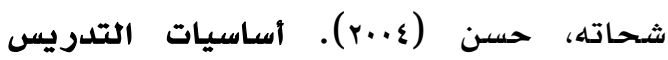

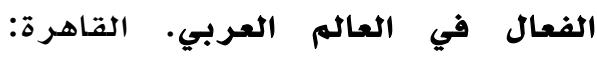
الدار المصرية اللبنانية.

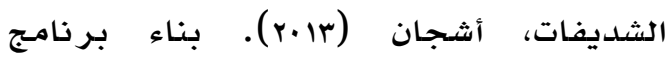
تعليمي قائم على مهارات التذوق الأدبي بالمستوى الإبداعي مـن خلاعل ملهي تدريس النصوص الأدبية للدى طلبة قسهم اللغلة فلهي العربية في كلية الآداب في الجامعة

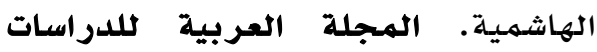

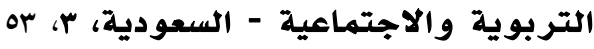
$.79-$ صببح، نورا (r) (r). مدى تحقق الكفايات اللغوية في طرائق التدريس والتذوق الأدبي في المرحلة الثانوية. رسالة ماجستير غير منشورة، جامعية البعث، الجمهورية العربية السوريـة.

حسن، أنعام (r/r). الذاء الانفعالي و علاقته باساليب التعامل مع الضغان الضغوط

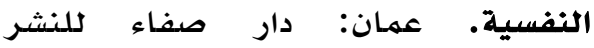

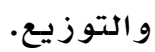

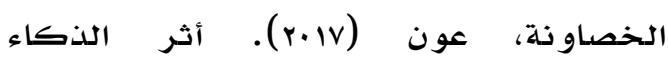
الانفعالي عند المعلمين في تحصيل طلبتهم للهمرحلة الابتدائية في إقليهم

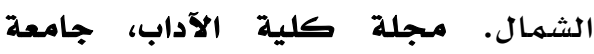

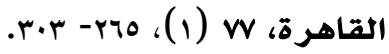


